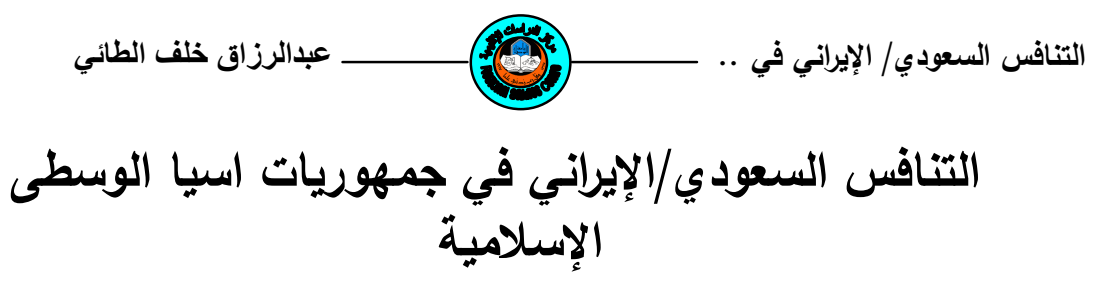

$$
\text { مدرس مساعد مركز الدراسات الإقليمية/جامعة الطائي محد الموصل }
$$

مستخلص البحث

ترك تفكك الاتحاد السوفيتي، فراغا سياسيا وامنيا في منطقة اسيا الوسطى، في

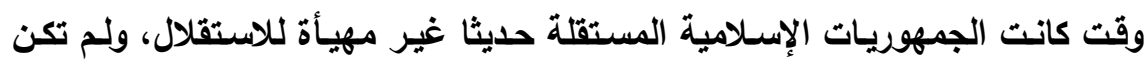
تمتلك هياكل وخبرات أساسية تمكنها من النهوض بأعباء الدولة الدديثة، مما جعلها

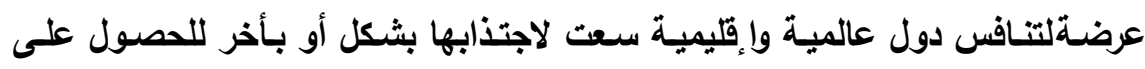

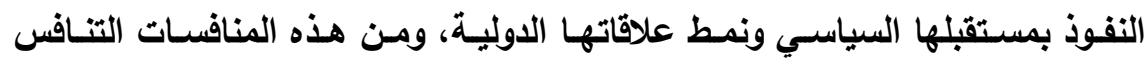
الضمني بين المملكة العربية السعودية وجمهوريـة إيران الإسـلامية،اللتان تستخدمان وندان

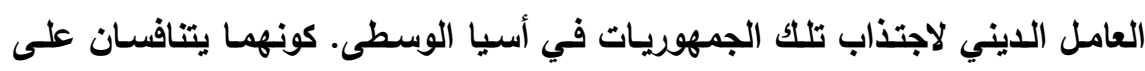

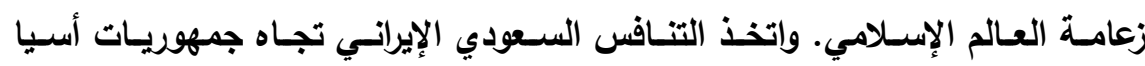
الوسطى أساليب وأنشطة عديدة تنصب في العمل على تعزيز العلاقات الدينية والثقافية

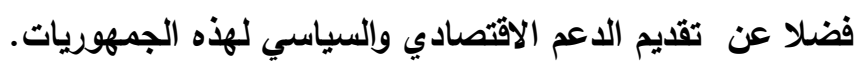

المقدمة

اثز تفكك الاتحاد السوفيتي بوصفه كيان سياسي وجغرافي في أواخر عام ، بدأت تتشكل كيانات سياسية مستقلة جديدة ضمن حدوده السـابقة، وكان من بينها جمهوريات أسيا الوسطى الإسلامية (تركمانستان، أوزبكستان

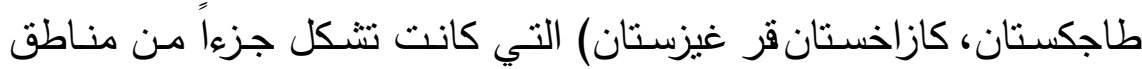
النفوذ الروسي والاتحاد السوفيتي على مدار أكثر من سبعة عقود. 
تـرك تفكـك الاتحـاد السـوفيتي، فراغـا سياسـيا وامنيـا في منطقـة أسـيا

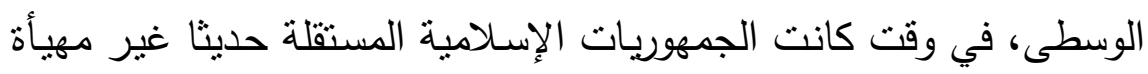
للاسـقاله، ولـم تكن تمتلك هياكل وخبـرات وبنيـات أساسية تمكنهـا مـن

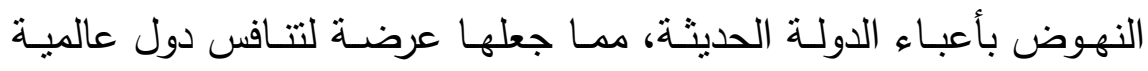

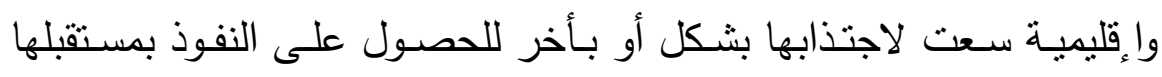
السياسي ونمط علاقاتها الدولية، ومن هذه المنافسات التنافس الضمني بين الضين المملكة العربية السعودية وجمهورية إيران الإسلامية،اللتان تستخدمان العامل

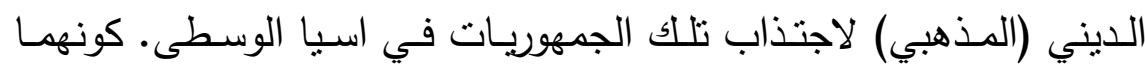
يتتافسـان على زعامـة العـالم الإسـالامي. واتخذ التـافس السـودي الإيراني

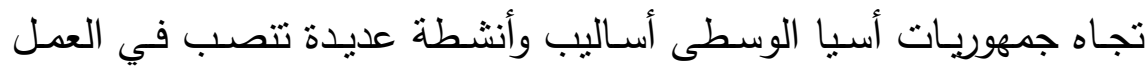

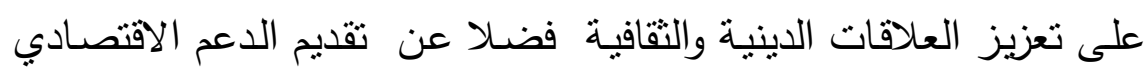

$$
\text { والسياسي لهذه الجمهوربات. }
$$

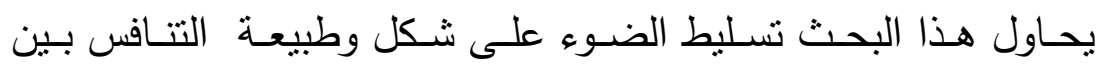

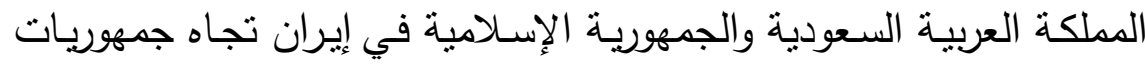

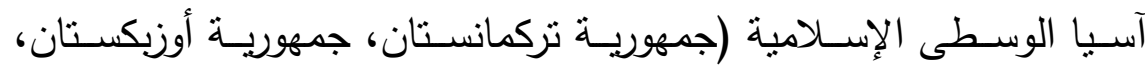

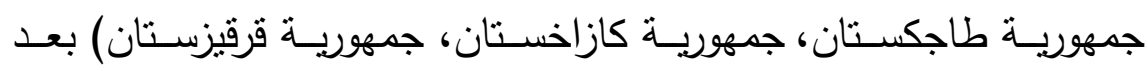
استقلالها من الاتحاد السوفيتي حيث بركز البحث على النصف الأول من

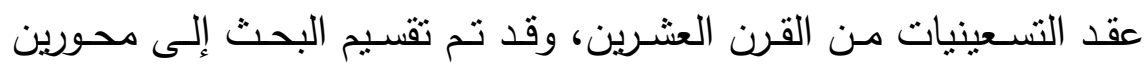
وخاتمة اشتملت على أهم النتائج التي توصل إلبها البحثي.

أولا : دوافـع التــافس السعودي_الإيرانـي تجـاه جمهوريـات أسيا الوسطى الإسـلامية : اولافية 
سعت كل من المملكة العربية السعودية و جمهورية إيران الإسـالية، اثر تفكك الاتحاد السوفيتي إلى تعزيز وجودهما الديني والسياسي في جمهوريات أسيا الوسطى المستقلة حديثا، ضمن التتافس الدولي التي شهدته هذه الدول بعد عام .وتكمن دوافع (السعودي الإيراني) في الاهتمام بجمهوريات

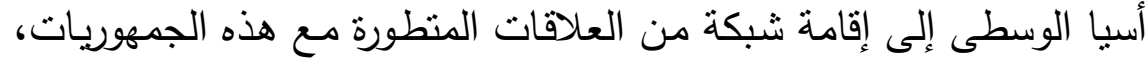
سيما إن بعضها يمتلك ثروات طبيعية كبيرة من النفط والغاز الطبيعي مها شجع إيران على الدخول بوصفها منافسا ومستثرا مع إمكانية نوظيف إيران لموقعها الجغرافي كمعبر لصسادرات وواردات هذه الدول الموصسوفة بالدول

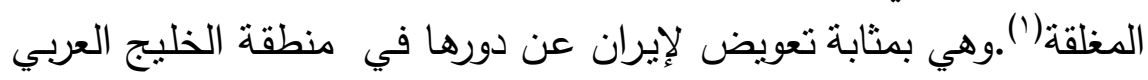

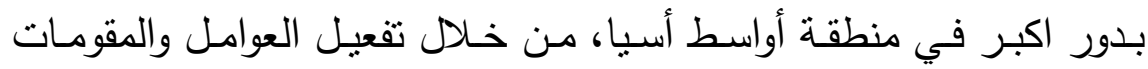
المشتركة مـع هذه الجمهوريات بعد توثيق العلاقات معها والحصـول على منى قدر اكبر من النفوذ السياسي فيها، ناهيك عن محاولة طرح النموذج الديني

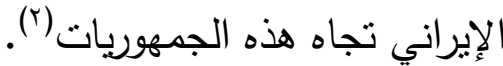
بينمـا كانــت دوافـع المملكـة العربيـة السـعودية تجــاه جمهوريـات أسـيا الوسطى تتصب حول الدوافع الدينية والسياسية التي تشكل القدر الأكبر من فن

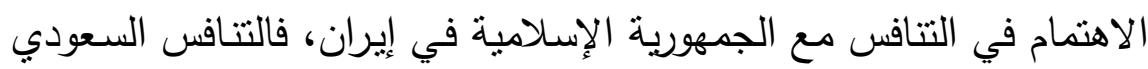

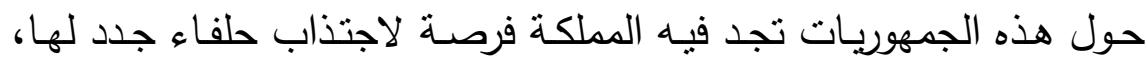
لاسيما أن معظم سكان هذه الجمهوريات من المسلمين، لذا سعت المملكة

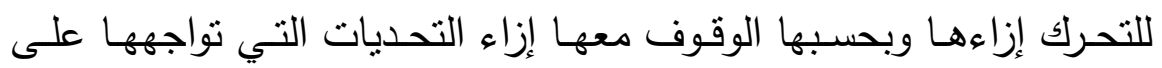
الأخص منجانب جمهورية إيران الإسلامية التي تتنافس واءياها على زعامة العالم الإسـامي (ז)، فالمملكة العربية السعودية دولة إسـامية تضم الحرمين الإنية

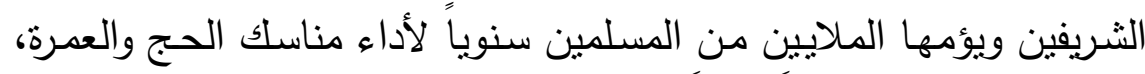

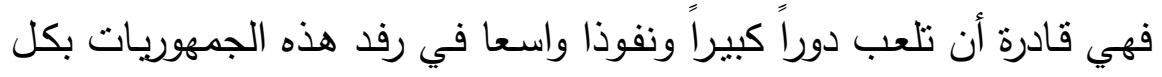

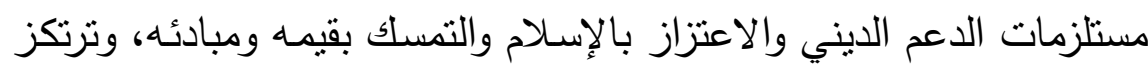

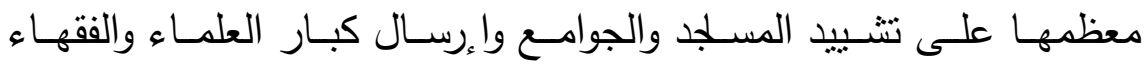


لإرشـادهم وتوجههم وطبع آلاف النسخخ من القرآن الكريم واءرسالها إلى هذه

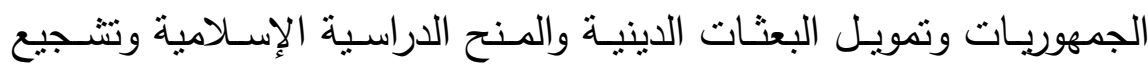

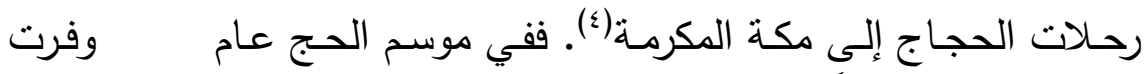

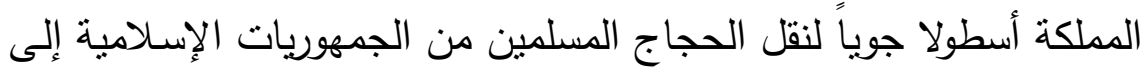
الحرمين الثربفين لأداء مناسك الحج والعمرة وبالعكس وهيأت لهم معاملة أفضل، كما زودتهم بالمصاحف الثريفة(0).

ثانيا : واقع التنافس السعودي - الإيراني تجاه جمهوريات أسبا الوسطى

بادرت كل من المملكة العربية السعودية وايران فور إعلان استقلال هذه

الجمهوريات إلى الاعتراف بها والعمل على إقامة أفضل العلاقات معها.

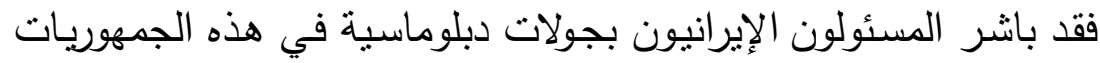

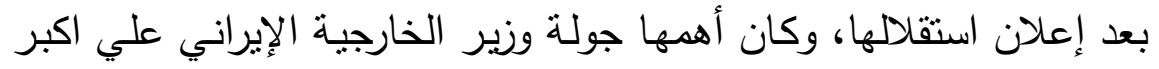

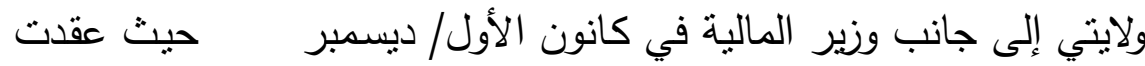

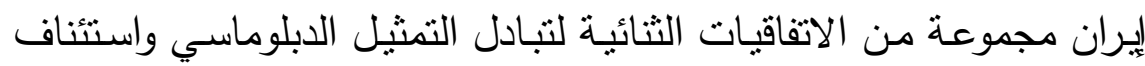

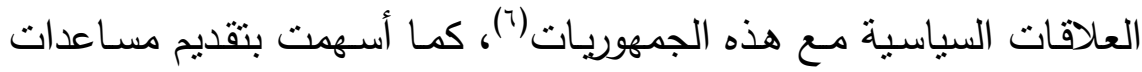
وقروض تراوحت بين - مليون دولار لكل منها سدد البعض منها بهيئة سلع استهلاكية تم تغطيتها من قبل البنك المركزي الإيراني (vل.

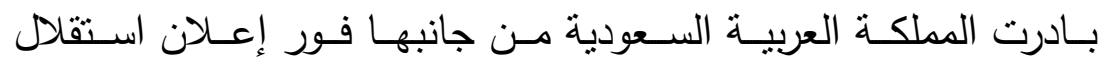
الجمهوريـت عبر قرار مجلس الوزراء السعودي بالاعتراف رسميا باعتبارها جمهوريات مستقلة ذات سيادة، وفي شباط/ فبراير قام وزير الخارجية

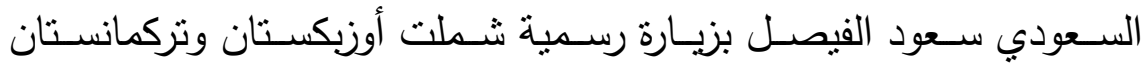
وطاجكستان، وخلال نلاك الزيارات شدد الوزير السعودي على أهمية منطقة آسـيا الوسـطى بالنسبة للمملكـة العربيـة السـودية. وتم خـلال هذه الزيـارة

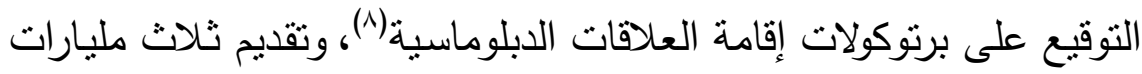


دولار كمعونـة مالية لهذه الجمهوريات(9)، وفي هذا إثـارة واضحة على أن

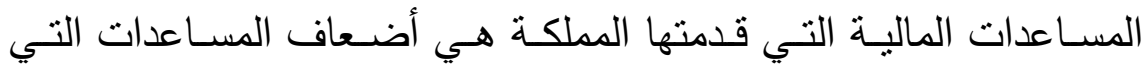

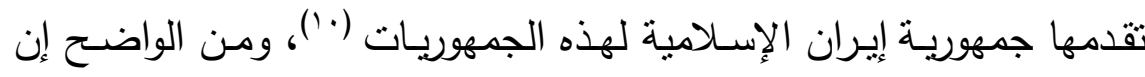
هذه البادرة تهدف لتسليط الضـوء على مدى الالهتمام العالي للمملكة تجاه

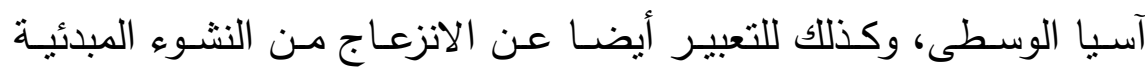
(I)

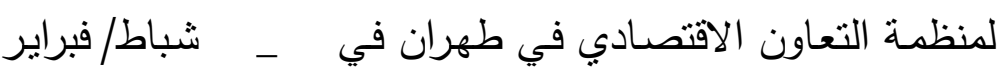
التي شعرت المملكة بأنها قد استبعدت منها عمدا من جانب إيران (rان"). كان الدافع الرئيس في إستراتيجية إيران من تشكيل المنظمـة هو تعزيز

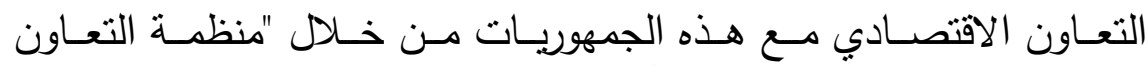

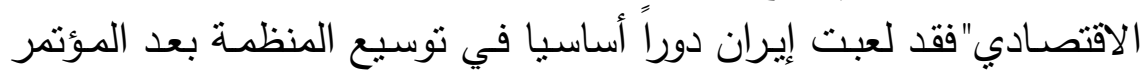

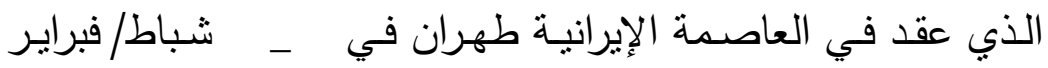
لتشـمل تركمانستان وأوزبكستان وقرقيزستان وطاجكستان وكازاخستان التي فئني

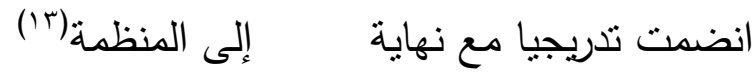
من جانبها نجحت المملكة بعض الثيء استخدام نفوذها الديني لحصول

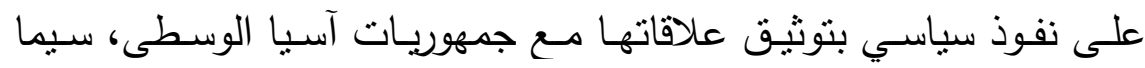

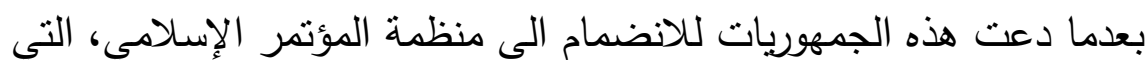

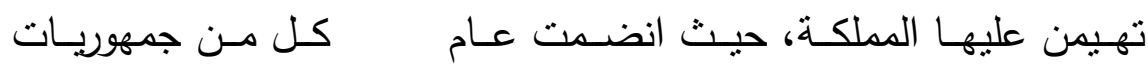

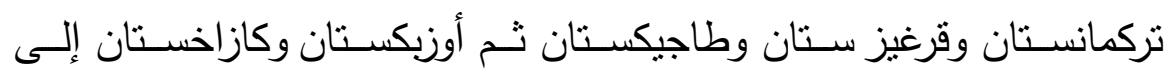

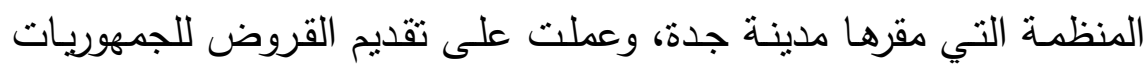
الإسالمية، عبر بنك التتمية الإسلامي التابع لمنظمة المؤتمر الإسلامي. وعي.

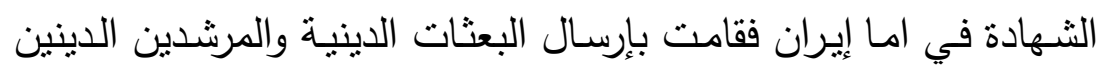

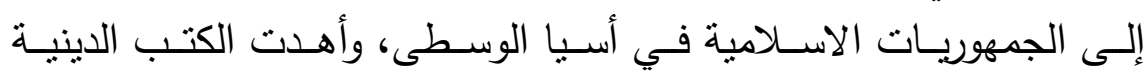
المختلفة، وخصصت نسب واسعة من مقاعد البعثات الدراسة في جامعاتها

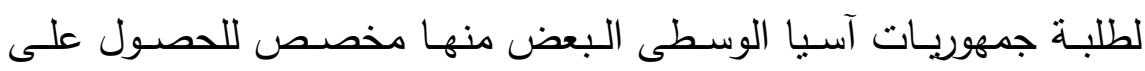
الدراسـات الدينية في الحوزة العلميـة الكائنة بـ (قم) وقدمت مساعدات لبنـاء 
مساجد ومدارس دينية في الجمهوريات كافة(؛) إلا أن النموذج الديني الذي

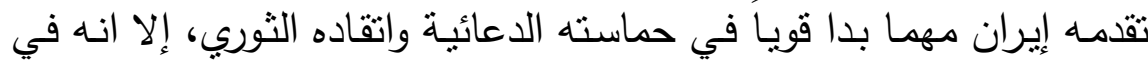

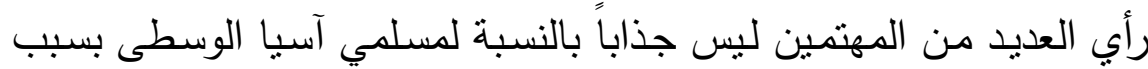

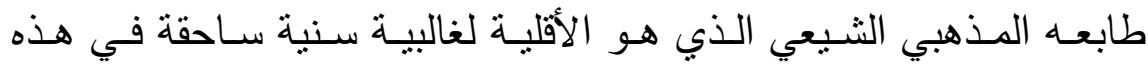

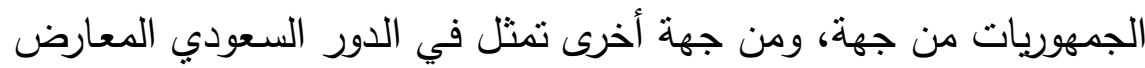

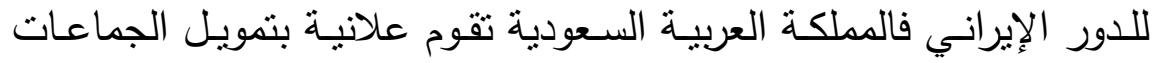

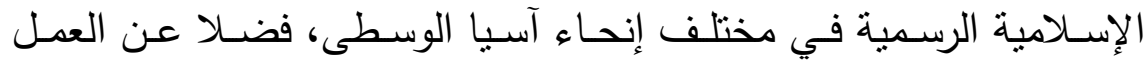
الدعوي النشط الذي يقوم بـه دعاة و نشطاء إسـلاميون من المملكة وبقيـة

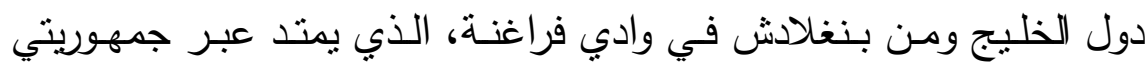
قرقيزستان وأوزبكستان.وتقدم المملكة كذلك منحسا دراسية لأفراد من أسيا

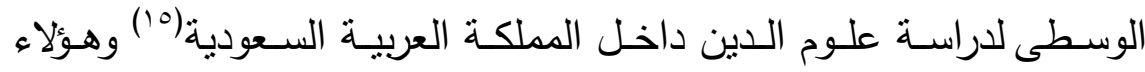

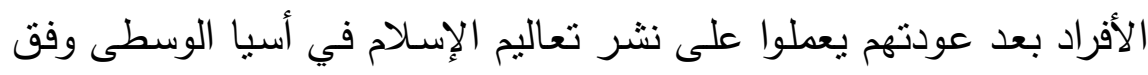
تعاليم المنهج السلفي للمملكة العربية السعودية.

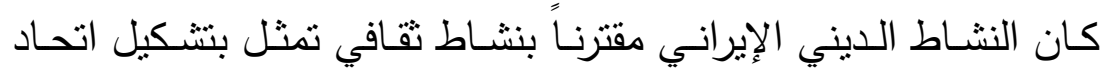

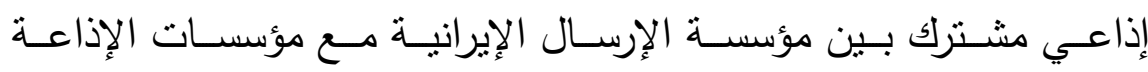

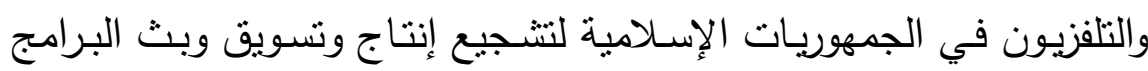
التي تعنى بالتقافة الإسـامية وتسـويق النمـوذج الديني الإيرانسي في هذه

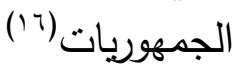

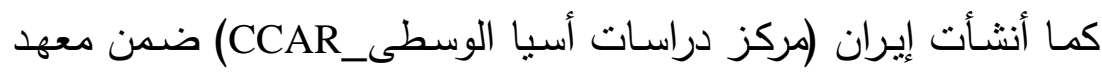

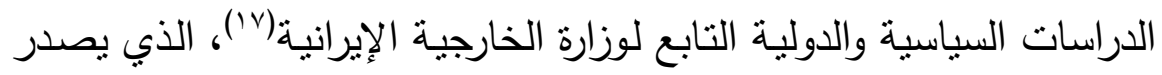
مجلة تحمل اسم(مطالعات اسياي مركزي وقفقاز) تعنى بالثؤون السياسية

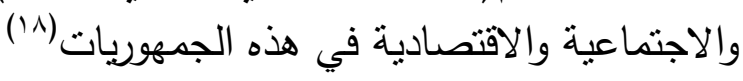

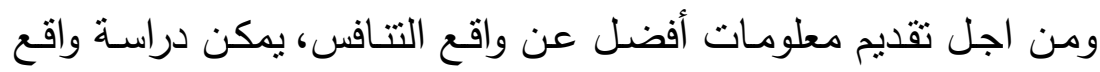
التنافس في كل جمهوريـة من جمهوريات أسيا الوسطى، وذلك ولك لاختلاف ظروف كل جمهورية، وأهميتها بنسبه لإيران والمملكة العربية السعودية: 


\section{- جمهورية تركمانستان}

تأتي جمهوريـة نركمانستان (9') في مقدمـة التوجهات الإيرانية نحو أسيان الوسطى إذ افتتحت فيها إيران أول سفارة لها في شباطان فبراير

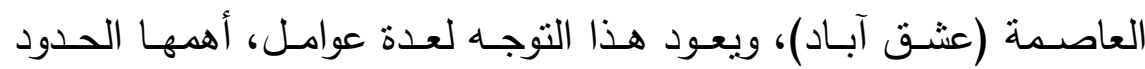

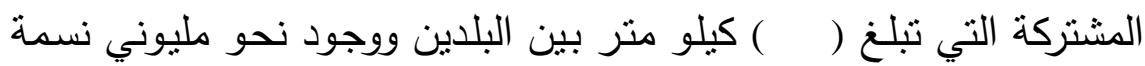

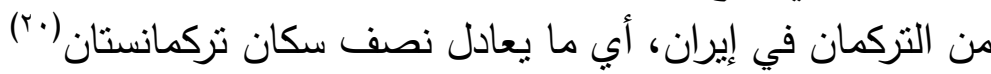

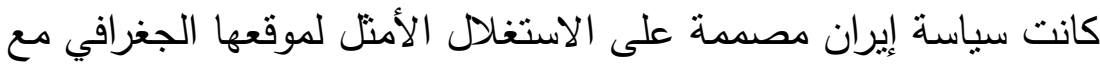
تركمانستان، التي تعد بوابـة مهمة لإيران نحو أسيا الوسطى. لذإللك عملت

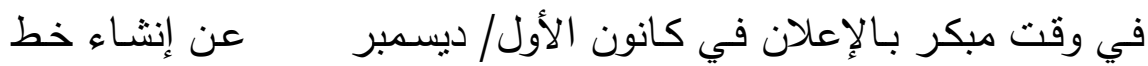

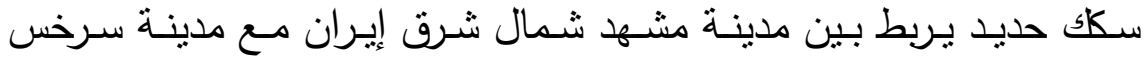

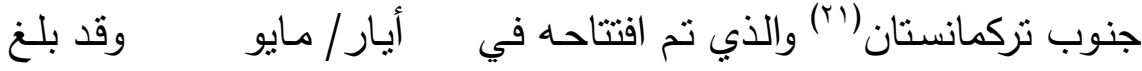
طوله نحو ( كيلومثر ومن شـان هذا الخط الحديدي توسيع العلاقات التجاريـة بين إيران ودول أسيا الوسطى ويسهر في جعل إيران بوابـة رئيسـة

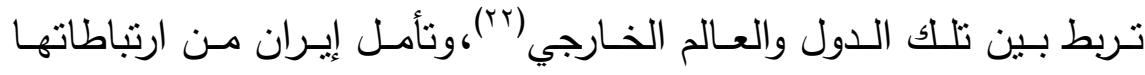
المتتامية بتركمانستان في مجالات النقل والمواصلات إن تمنحها موطئ قدم

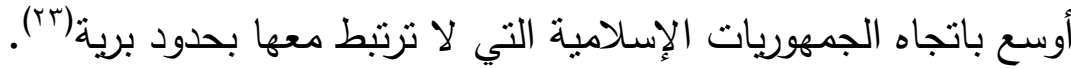

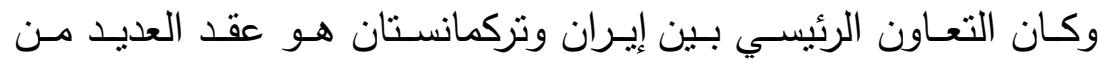

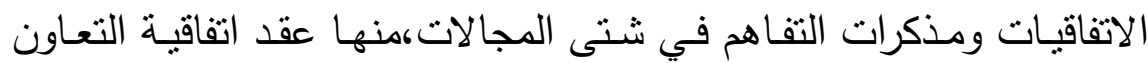

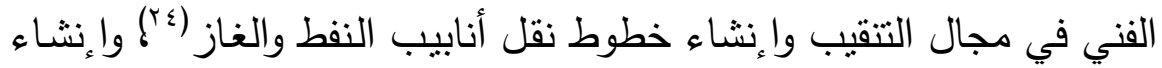

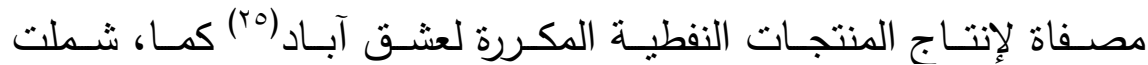

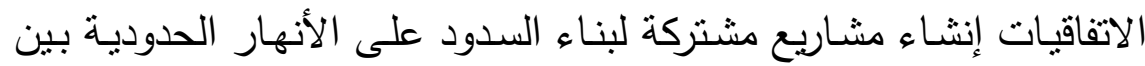

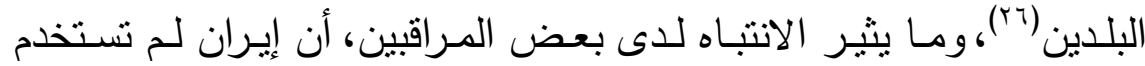
الدعايـة الدينيـة إلى درجه كبيرة في هذه الجمهوريـة حرصسا على استقرارها 
سياسيا(YV) لكن على غرار جمهوريات أسيا الوسطى الأخرى، تلقت جمهورية

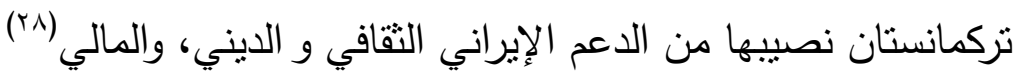

وكانت أفاق التعاون الاقتصادي والتقافي بين إيران و تركمانستان بمثابة الإنية

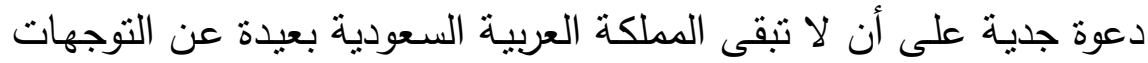

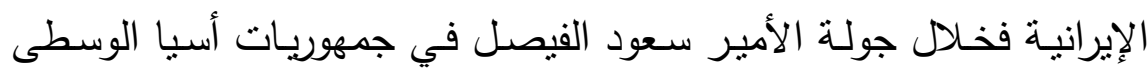

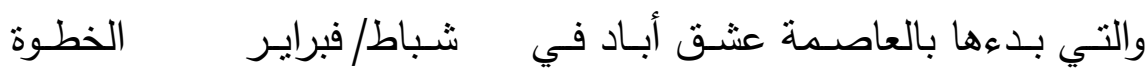

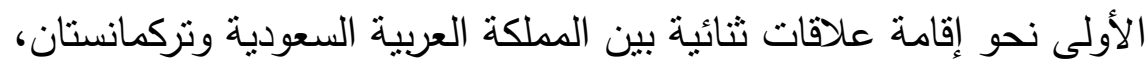

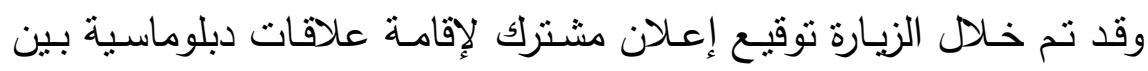

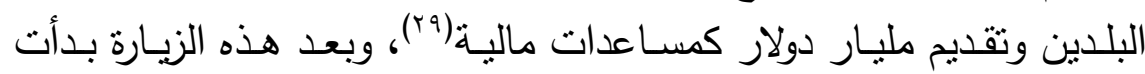

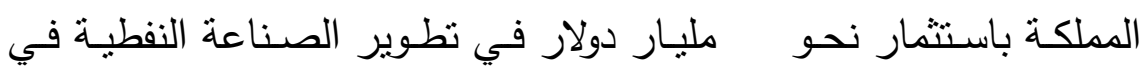
تركمانستان (r. (r)

أمـا على مستوى توجهات القطاع الخاص فقد استطاع رجل الأعمال

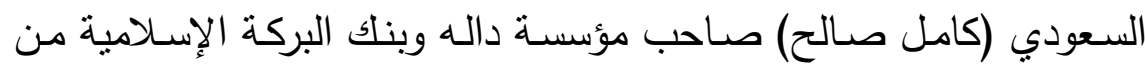

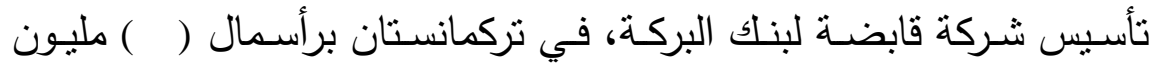

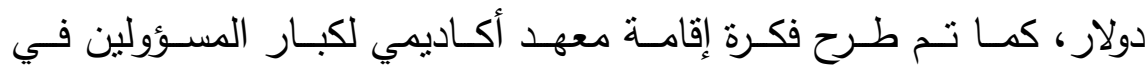

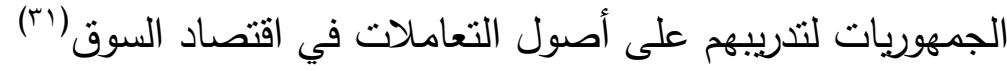

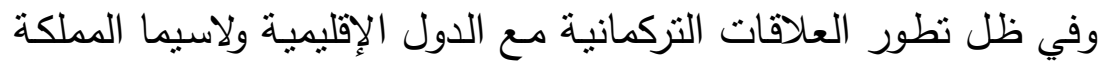

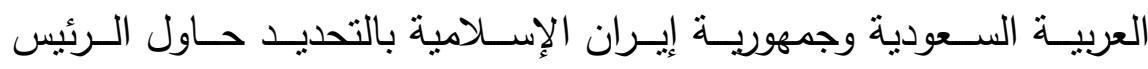

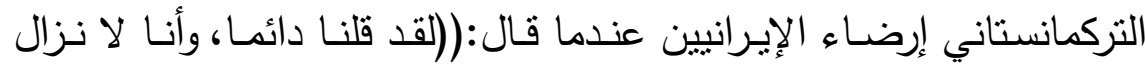

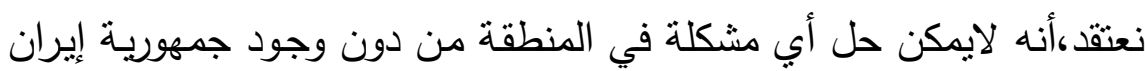

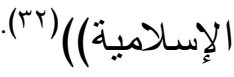

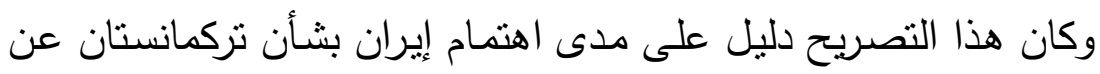
بقية الدول الإقليمية ومنها المملكة العربية السعودية. 


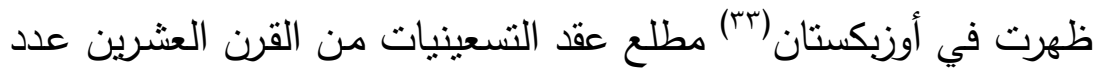
من الأحزاب السياسية الإسـلامية والتي أصبحت أنشط أنشان اثر تفكلك وانهيار

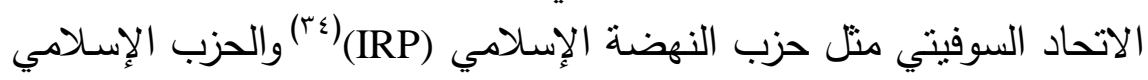
الديمقراطي (IDP). وهذا الأخير دعا علنا إلى إقامة دولة لينية على غرار

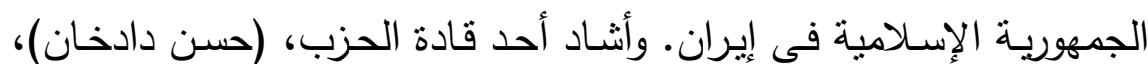

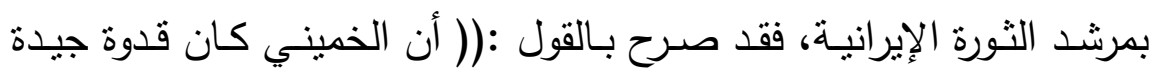
بالنسبة لنا)). ودعا إلى تطبيق الثريعة الإسـالامية على المجتمع الأوزبكي.

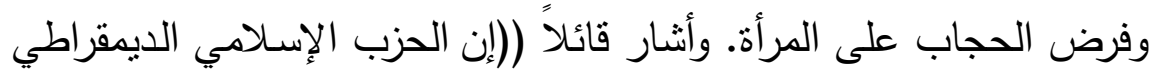

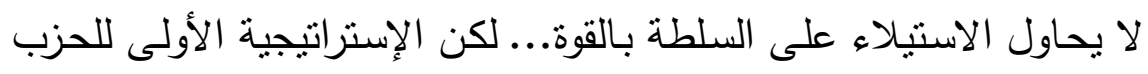
هي توحيد المسلمين و تثقيف الجيل الجديد على روح الإسلام)(ب(ro). وقبل الإعـلان النهائي عن تفكلك الاتحاد السوفيتي، قام وزير الخارجيـة الإنية

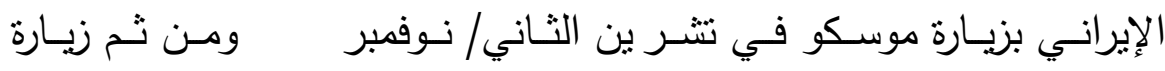
جمهورية أوزبكستان، وأعلن في الزيارة عن البدء في تأسيس الجمعية الثقافية لتونية بين إيران وأوزبكستان • و منذ ذلك الحين، كرست الحكومة الإيرانية الاهتمام الأكبر للعلاقات التقافية والدينية مع أوزبكستان (זَr).

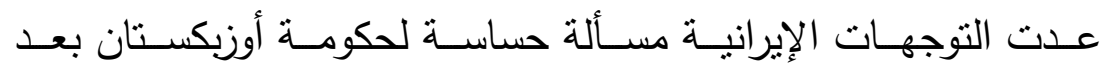
الاستقلال، فقد اتهم الرئيس الأوزبكستاني إسـلام كريموف ( )، إيـران

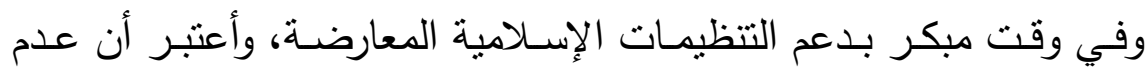
الاستقرار السياسي في المنطقة وجذور الحرب الأهلية في طاجكستان، هو

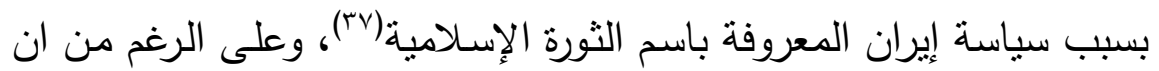

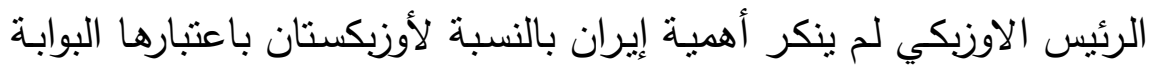

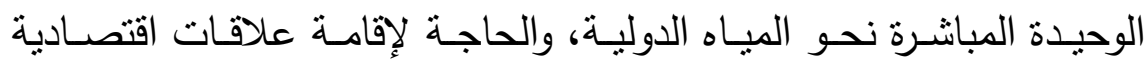

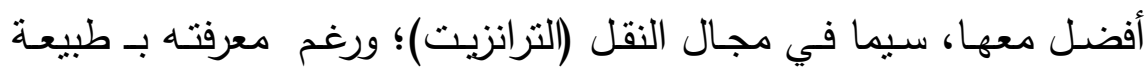

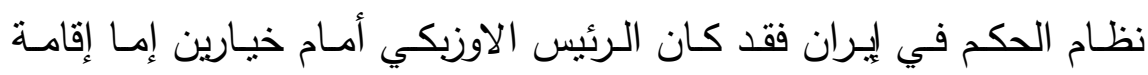

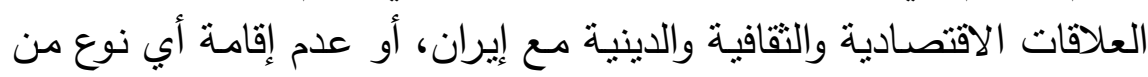


العلاقـات، لـذلك اختـار الخيـار الأول، فقــ قـام الـرئيس الاوزبكي إســلام كريموف بزيارة طهران في عام وقع خلالها على عدد من الاتفاقات

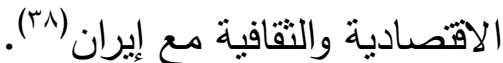
ورغم ذلك ظلت العلاقات الثنائية بين البلدين يشوبها الثك والحذر ـ فعلى سبيل المثال، حذرت الحكومة الأوزبكية من أنها سوف تنسحب من منظمة لعنة

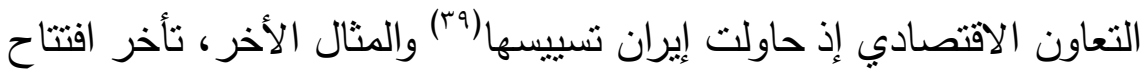
الأسبوع الثقافي الإيراني في أوزبكستان يومين عن الموعد المقرر لله، وذلك الكانك بسبب التفتيش الدقيق من قبل الأمن الاوزبكي لجميع الكتب التي قدمتها

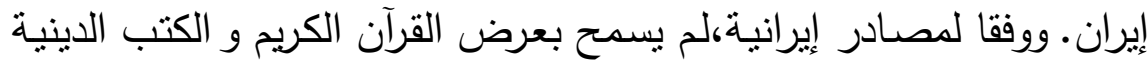

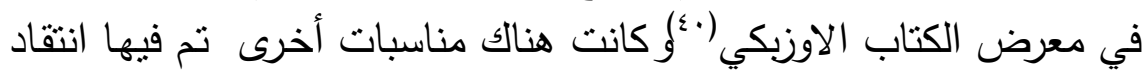

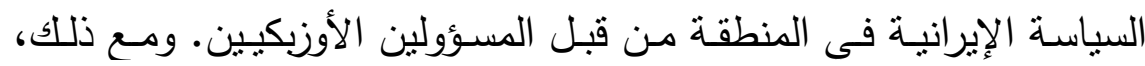

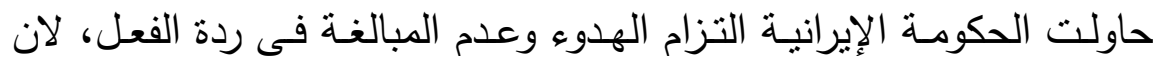

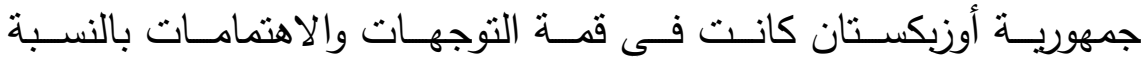
لإستراتيجية إيران ودورها في آسيا الوسطى بشكل عام (اء)، ولم تكن إيران تريد أن تفسح المجال لتوجهات المملكة العربية السعودية لكسب موطئ قدم اكبر في أوزبكستان. لان إيران تعرف ارتفاع نسبة المسلمين (السنة) في لوهي

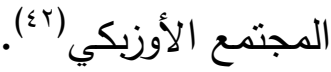
اما المملكة العربية السعودية فقد عملت على انتهاج إستراتيجية مزدوجة في أوزبكستان، فعلى الرغم من أنها تدعم التنظيمات الدينية، فقد كانت تقدم

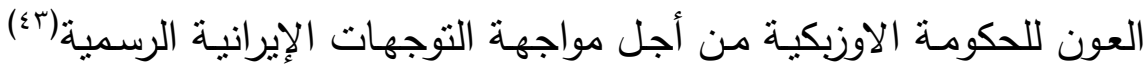

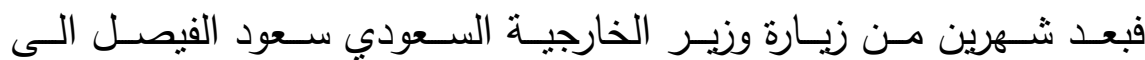

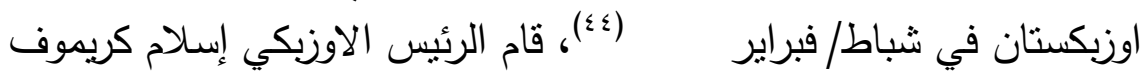

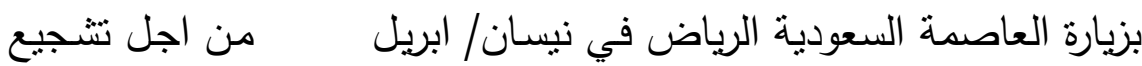

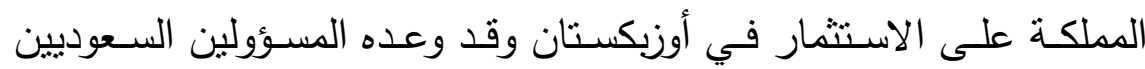
بدراسة العرض الاوزبكي وعند عودته تم تحميل الطائرة التي تقله بـ إعداد 
كبيرة من نسخ القران الكريم، وفي أيار / مايو من العام ذاته، زار العاصمة

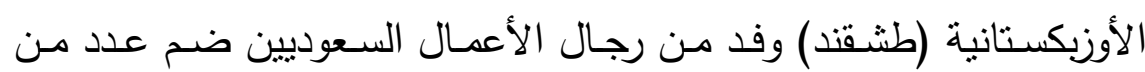
أصحاب البنوك الإسـامية، لأجل الإطلاع عن مدى إمكانات الاستثمارات

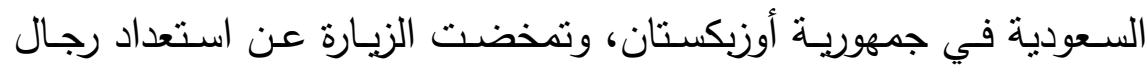

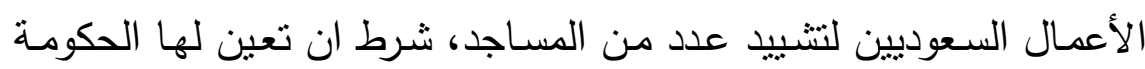
السعودية أئمة سعوديين، فرفضت أوزبكستان هذا العرض لافتنة انتباه رجال

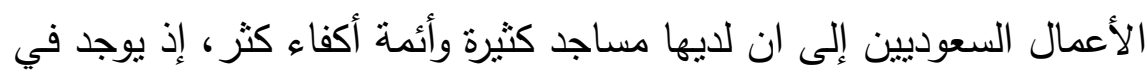

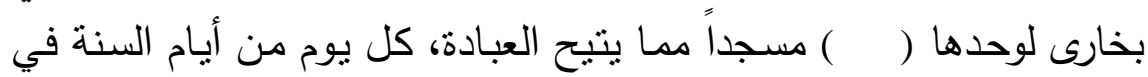
مسجد جديد(؛0).

في ذات الوقت قامت واحدة من أكبر الشركات السعودية بالتوقيع على هي

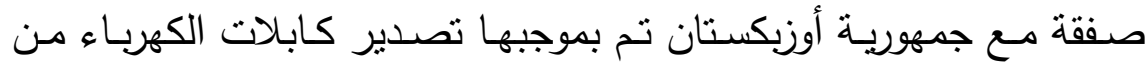
المملكة مقابل الحصول على منتجات النحاس والقطن من اوزبكستان. كما

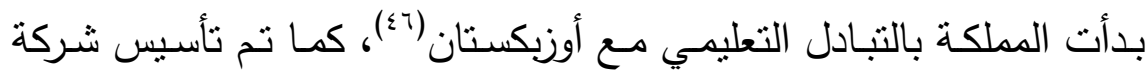
قابضة لبنك البركة في أوزبكستان برأسمال قدره ( مليون دولار (vis).

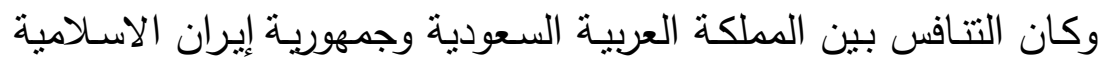
في منطقة وادي فرغانة في أوزبكستان على أثنده، حيث يعيش هنالك أكثر

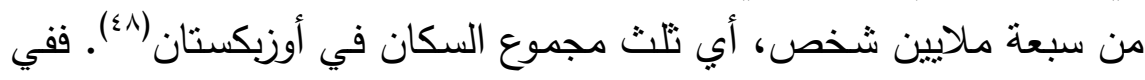

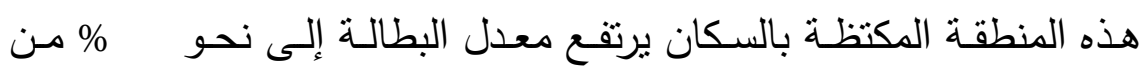

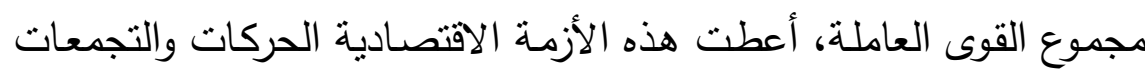

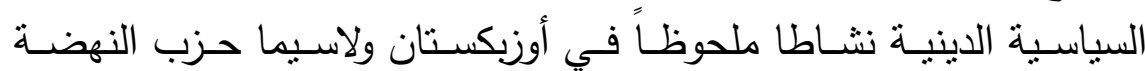
الإسلامي ومنظمة حركة أهل السنة(و؛ة).

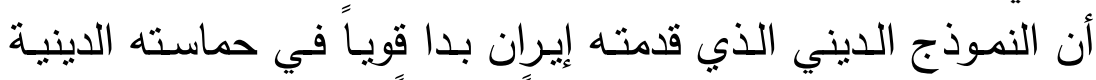

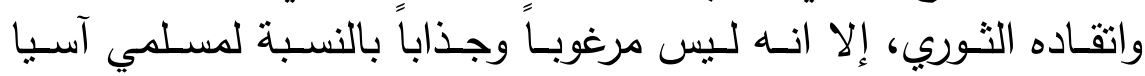
الوسطى بسبب توجهه المذهبي (الثيعي) في مجتمعات إسلامية ذات

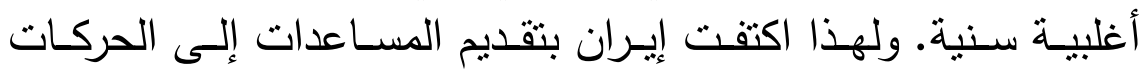




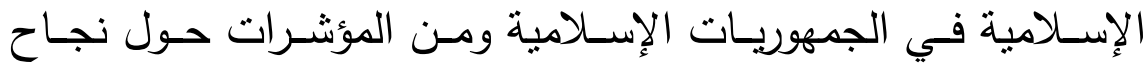

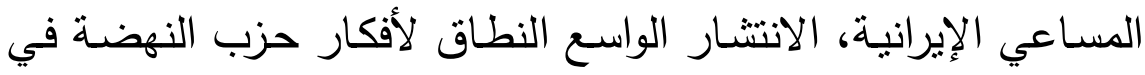

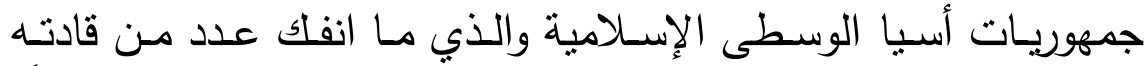

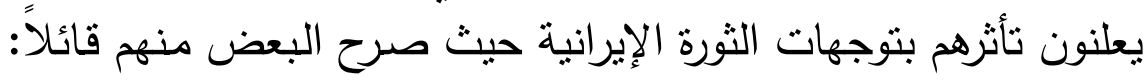

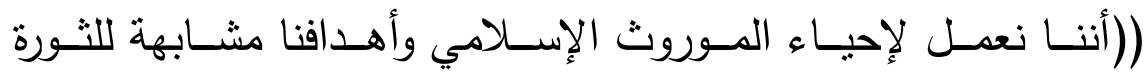

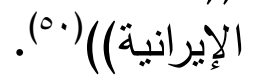

وعلى الرغم من انتشار أفكار حزب النهضـة الإسـامي بين أوساط

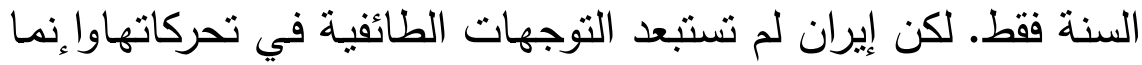

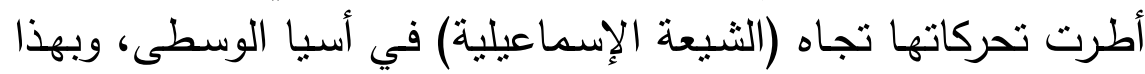

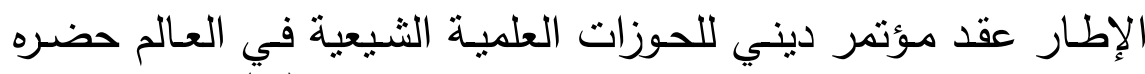

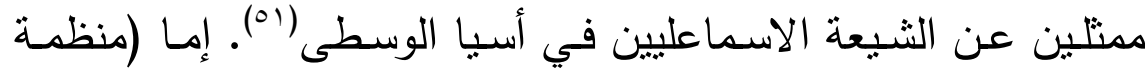

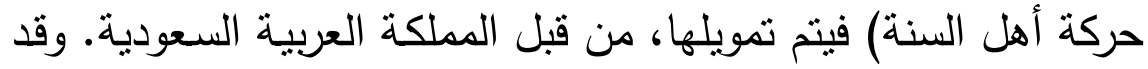

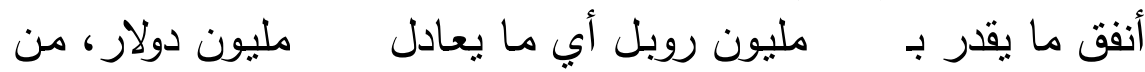

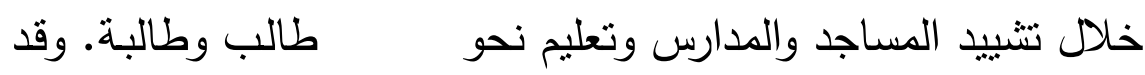

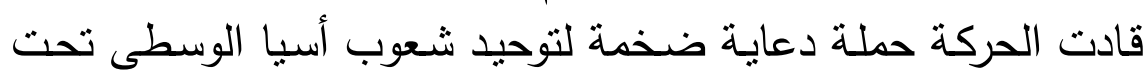

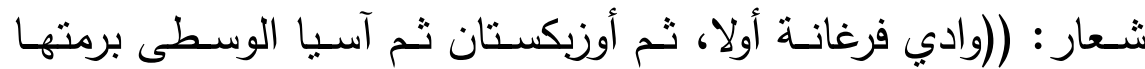

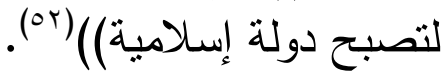

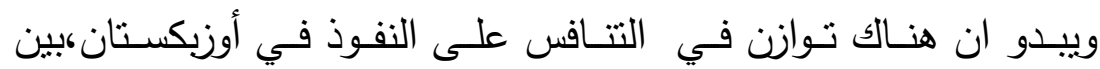

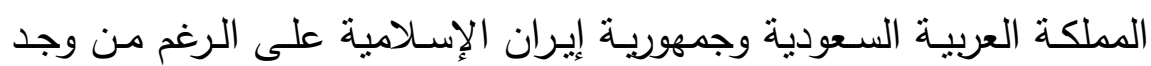

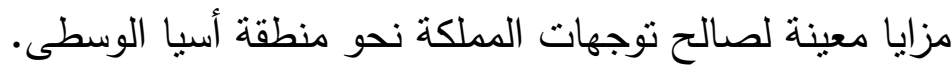

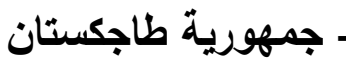

منذ البداية عملت إيران على إلحاق جمهورية طاجكستان (or) ضمن دائرة

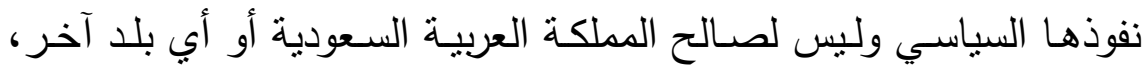

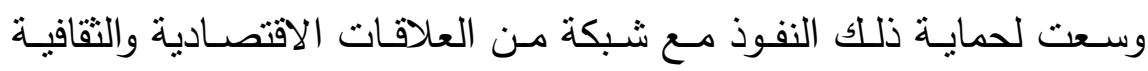


والسياسية. على كل المستويات(\&)، واعتبارا من عام كانت إيران تذعم مجموعات مختلفة من التجمعات الإسلامية في طاجكسنان، مثل حزب التبات

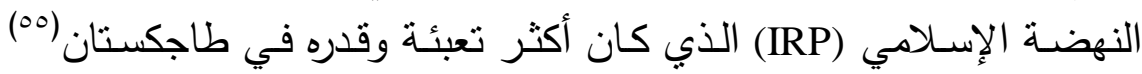
واءلى جانب دعم الجماعات الإسـالاية، قامت الحكومة الإيرانية بعد إعلان استقال طاجكستان بتقديم عدة مبادرات رسمية منها التعهد بتدريب الطاقم

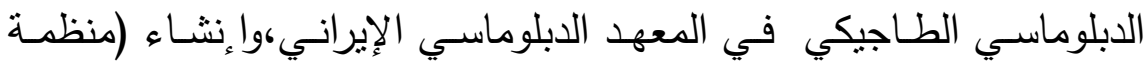
اللغـة الفارسية) في شباط/ فبرير والتي كان هدفها دعم المفردات الإيل

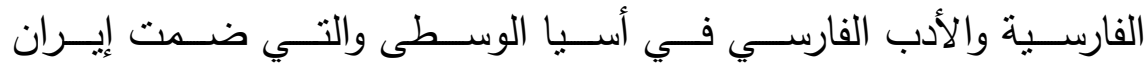
و طاجكستان (10). وقبل تموز / يوليو كانت إيران قد زودت جمهوريـة

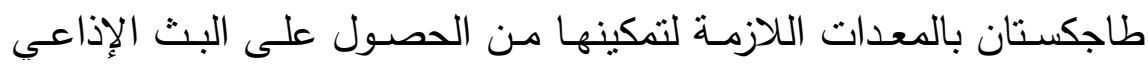
والتلفزيونى، والتى بدأت ببث برامج باللغة الفارسية في الإذاعة والتلفزيون

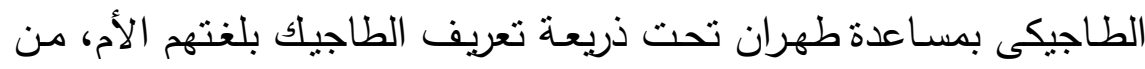

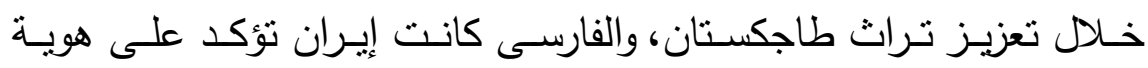

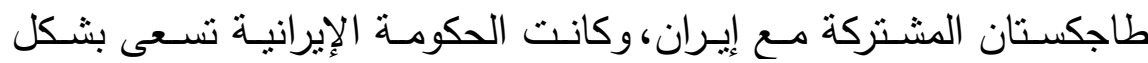

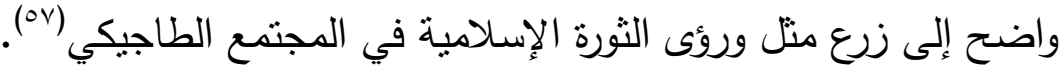

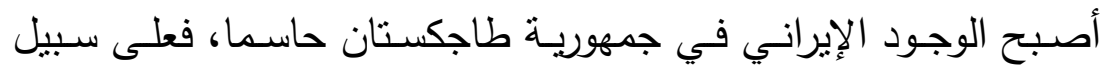
المثنال، في تشـرين الأول/ أكتـوبر

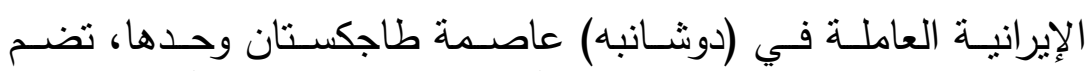

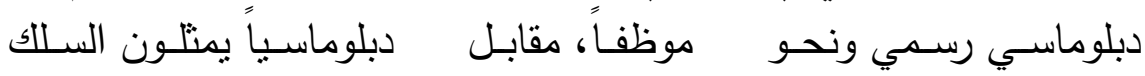

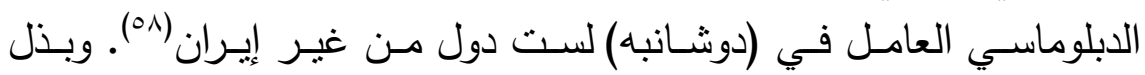
الدبلوماسيين الإيرانيين العاملين في (دوشانبه) قصارى جهودهم لتقديم الدعم لطاجكستان الذي فاق دعم المملكة العربية السعودية وباقى الدول منفردة.

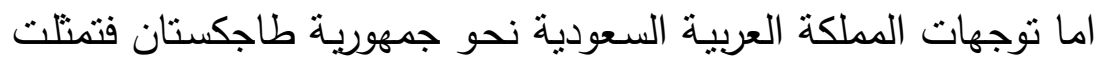
بزيارة وزير الخارجية السعودي سعود الفيصل لـ دوشانبه فى شباط / فبراير

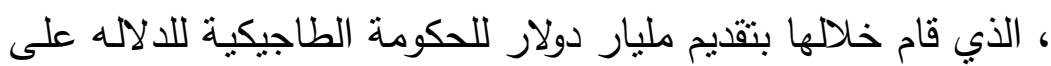


مدى الاهتمام السعودي في جمهورية طاجكستان، ورغبة قوية بمنافسة النفوذ

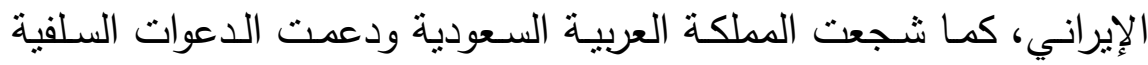

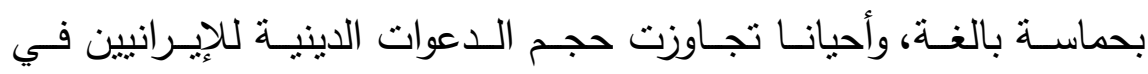
طاجيكستان، فضلا عن ذلك كان الطاجيك، أكثر ميلا إلى السلفية الدينية. بل أن العديد من علمـاء الدين الطاجيك وقادة المعارض الإسـلامية ومنهم

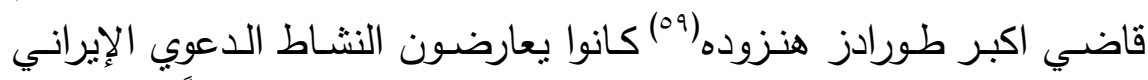

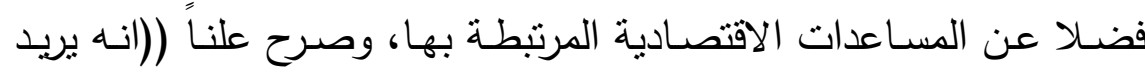

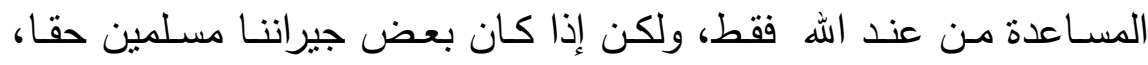

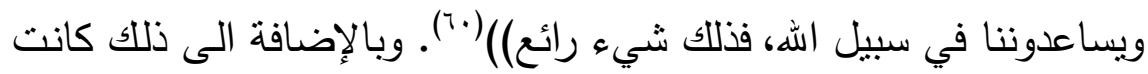

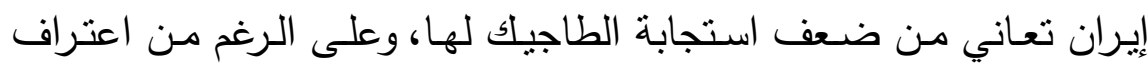
إيران أن الطاجيك يمتلكون الثقافة الفارسية ولكن لا يمكنها تو جيه الطاجيك

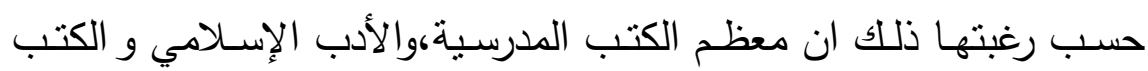

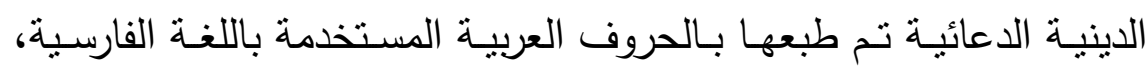

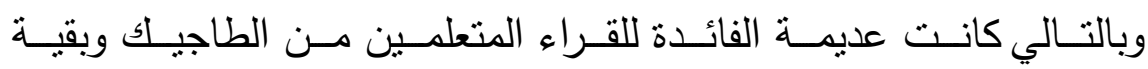

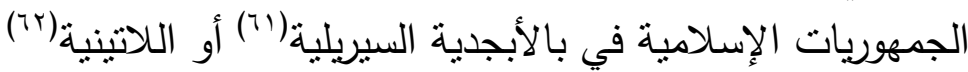
نشطت التوجهات السعودية في جمهورية طاجكستان وكانت تعارض بلان الإنية

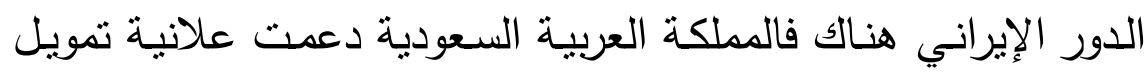
الجماعات الإسلامية الرسمية في مختلف إنحاء أسيا الوسطى، بما فيها دعائها طاجكستان فضلا عن العمل الدعوي السلفي النشط فيها(بآ).

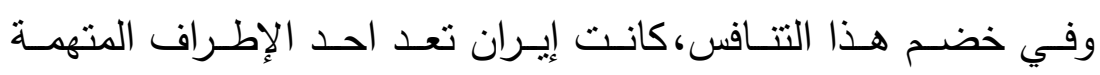

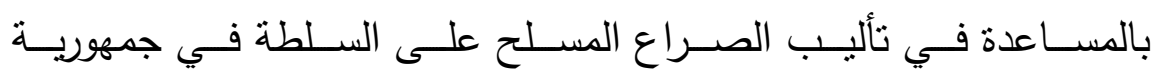

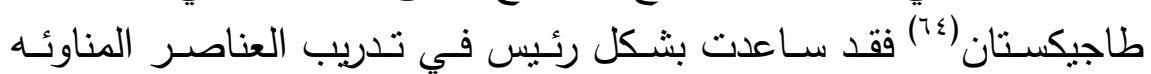

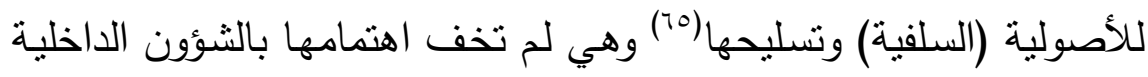

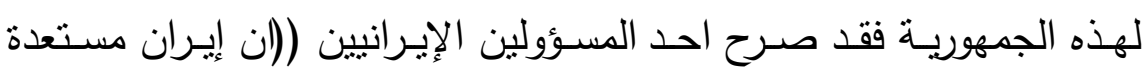

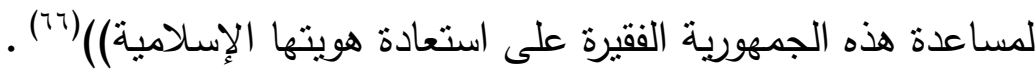


إلا ان الموقف الإيراني الداعم للمعارضة الإسلامية المسلحة لم يكن هو

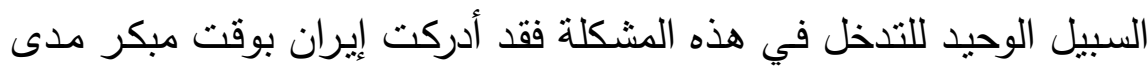

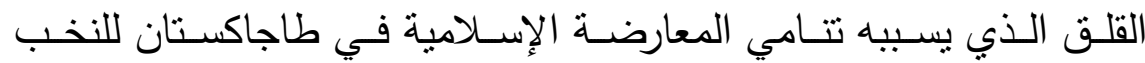
الحاكمة في أسيا الوسطى الأمر الذي يهدد بالخطر مجمل النشاط الإيراني

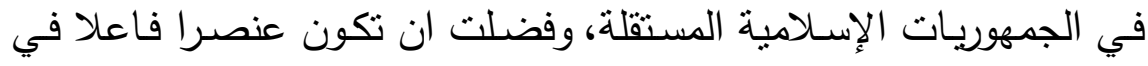
إقناع الإطراف المتتازعة باللجوء الى المفاوضـات وتم فعلا عقد مفاوضات

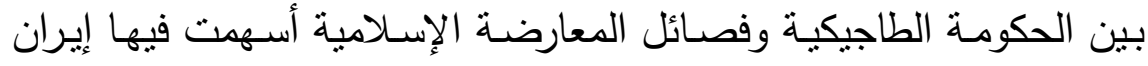

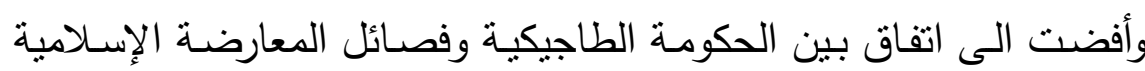

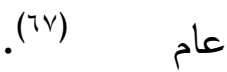
لقد فاق دعم إيران دور المملكة العربية السعودية وبقية الدول منفردة في طاجكستان، لذلك يلاحظ ان هناك دور اكبر لإيران في هذه الجمهورية على دور حساب المملكة العربية السعودية.

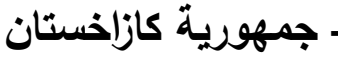

يتمثل التتافس السعودي الإيراني في جمهورية كازاخستان (^^) في مجال الحصول على استثمارات اقتصادية، إذ تمتلك كازاخستان ثروة طبيعية كبيرة من النفط والغاز، وكان لامتلاك كازاخستان ساحل على بحر قزوين، وقربها

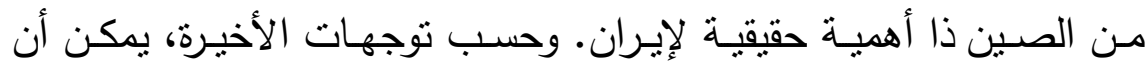
تعمل كازاخستان كحلقة وصل بين إيران والصين في إحياء مشروع (طريق لهن

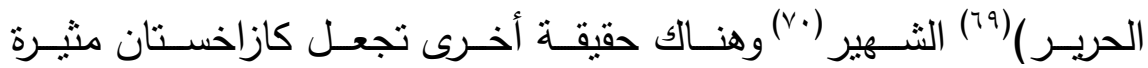

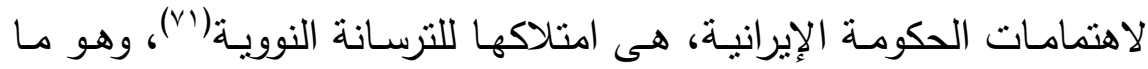

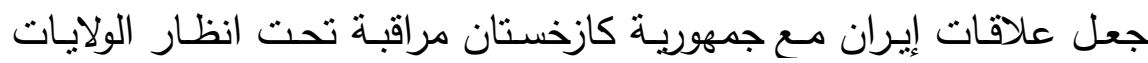

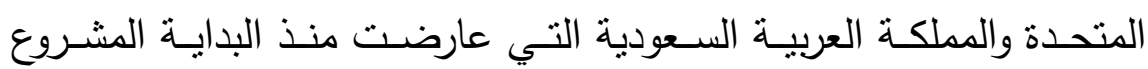
الإيراني في امتلاكها قدرات نووية(Vr) وكان لإيران مبادرة مع كازاخستان عام المات نجم عنها إنشاء "منظمـة تعاون بحر قزوين " التي تربط بين إيران 


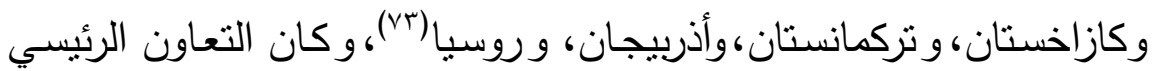

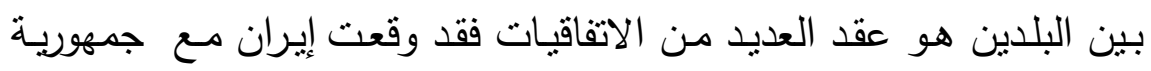

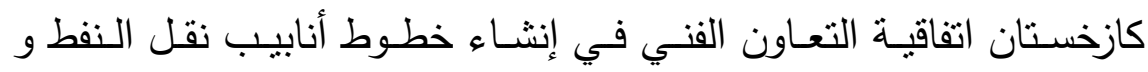

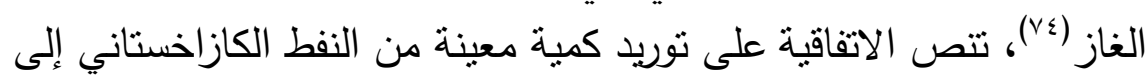
إيران عبر بحر قزوين فيما تقوم إيران بتصدير نفس الكمية من النفط عبر التوريه

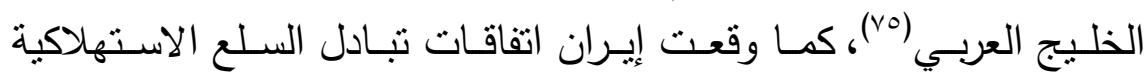

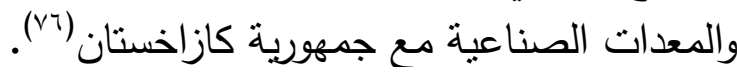
اما المملكة العربية السعودية فقد كان هناك بنك سعودي رأسماله ( )

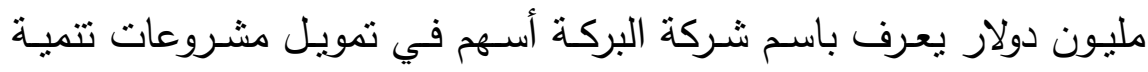

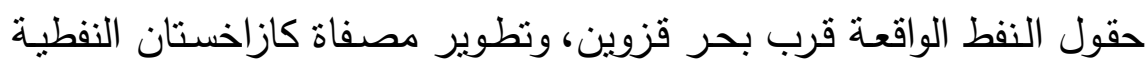

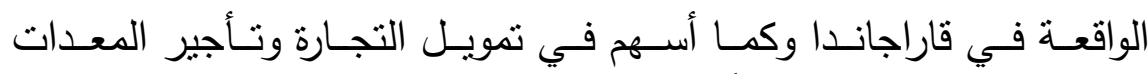

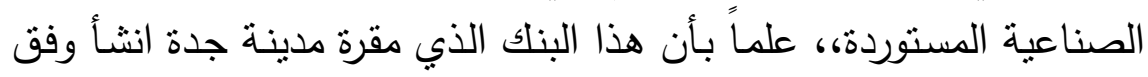

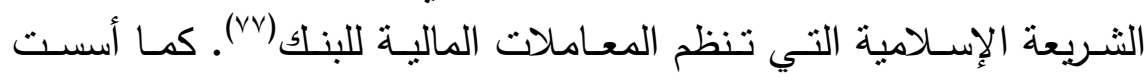
مجموعة من رجال الأعمال السعوديين (الثركة الدولية للاستثمارات في دول لإنيات

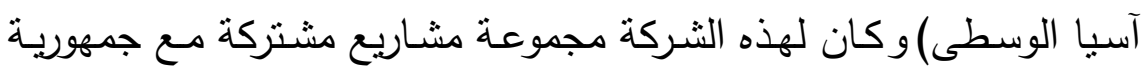

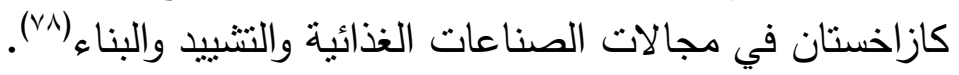

\section{- جمهورية قيرغيزستان}

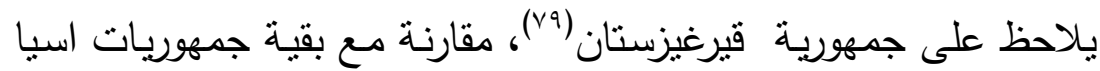

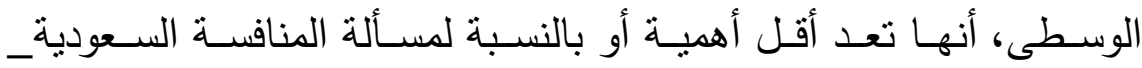
الإيرانية(·^). إذ أولت جمهورية قيرغيزستان اهتماما كبيرا في تحسين علاقتها

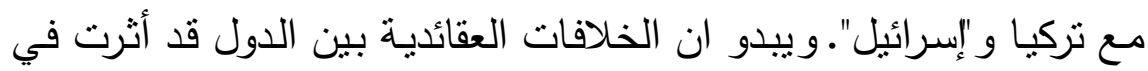

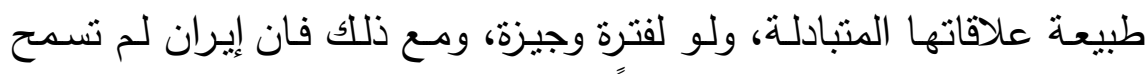

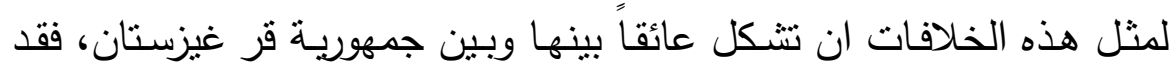
حدث على سبيل المثال ان اعترفت قر غيزستان بالقدس عاصمة لـ "إسرائيل" 
في كانون الثاني/ يناير وبسبب ذلك تم إلغاء زيارة وزير الخارجية الإيراني الى قر غيزسـتان، إلا أن إيـران استضـافة الـرئيس القرغيزي عسيكر

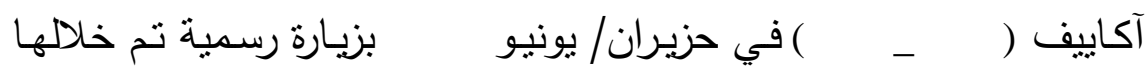

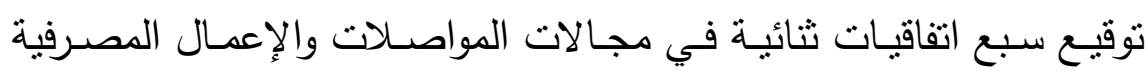
وتبادل السفارات والتعليم والسياحة والنقل (1).

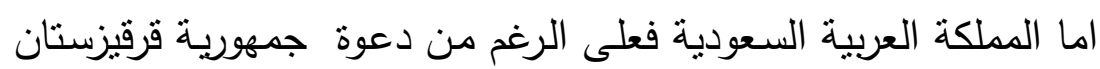

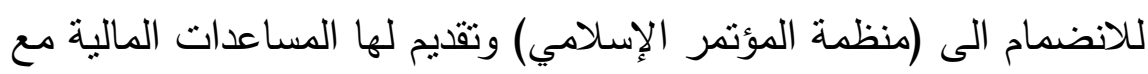

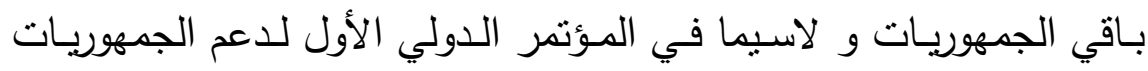

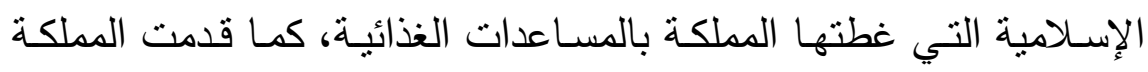

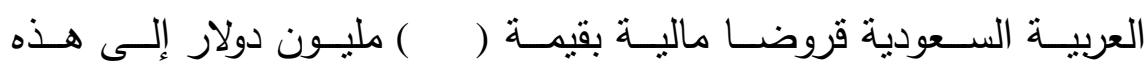

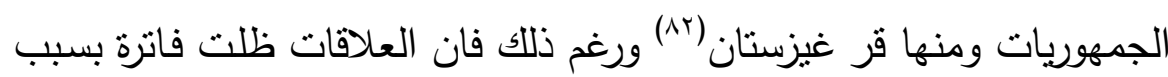
تحفظها على النشاط الإسرائيلي في جمهوريسة قرقيزستان وعلاقات فئها المميزة

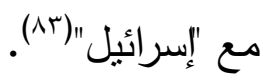

الخاتمة

ترك تفكك الاتحـاد السـوفيتي، فراغـا اسـتراتيجيا جزئيـاً أو كليـاً في التهي منطقة اسيا الوسطى، ناهيك عن إن الجمهوربات الإسـلامية المستقلة

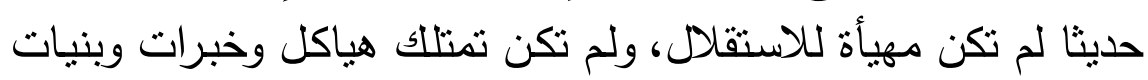

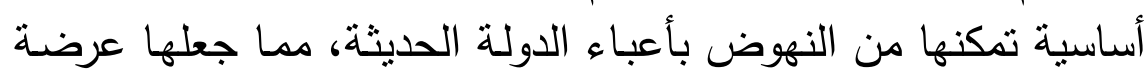

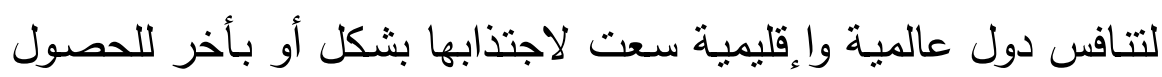

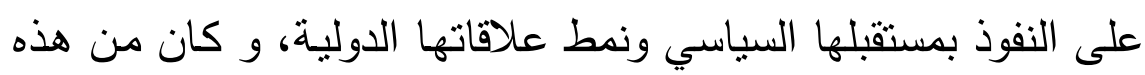
التتافسـات التـافس الضـمني بين المملكة العربيـة السـودية وجمهوريـة

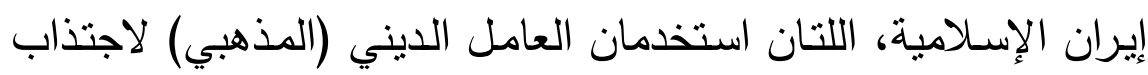
تللك الجمهوريات في اسيا الوسطى. كونهما يتتافسان على زعامة العالم الإسلامي. 
ومن خلال عرض سباق التتافس السعودي الإيراني على النفوذ في

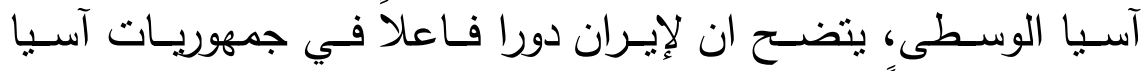
الوسطى انطلاقاً من القرب الجغرافي الذي يربط دول هذه المنطقة بها لإنان

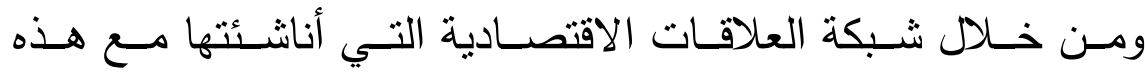

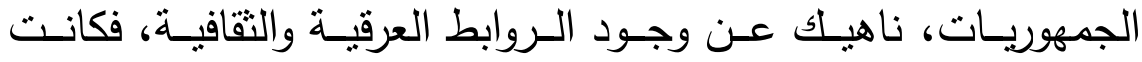
ومازالت منطقة آسيا الوسطى تشكل المتنفس الحيوي لتتمية العلاقات معها وجزءاً من استراتيجياتها وعلى مختلف المستوبات، وعلى وعلى الرغم

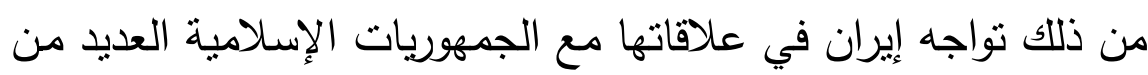

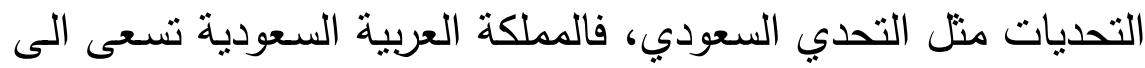
إضعاف النفوذ الإيراني الديني (المذهبي) والسياسي في اسيا الوسطى،

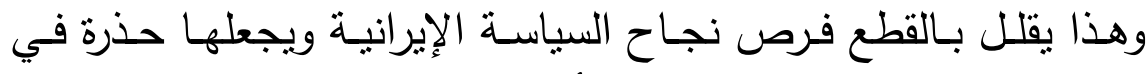
التعـاطي مـع القضـايا التي يمكن أن تثير المملكة العربية السـعودية. و لكن على الرغم من ذللك فلا تزال الأولوية في اهتمام إيران هي منطقة

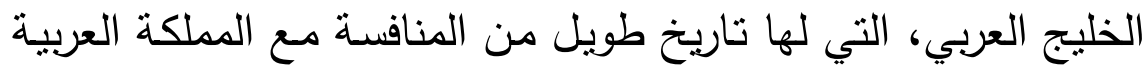
السـودية والتي تؤئز بشكل اكبر على طبيعـة العلاقات السعودية -

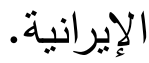




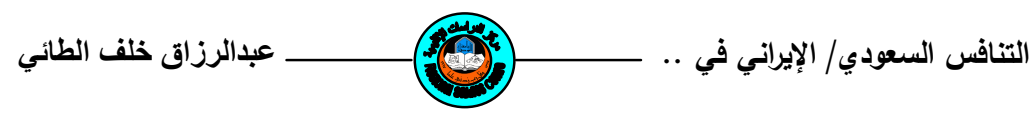

\title{
Saudi-Iranian competition in the republics of Central Asia, the Islamic
}

\author{
by : Aldal Razag Khalaf Mohammed al-Tai \\ Assistant lectures, Centre for Regional Studies/University of \\ Mosul
}

\begin{abstract}
The disintegration of the Soviet Union leave , a political vacuum and security in the region of Central Asia, at a time when the Islamic republics of the newly independent unprepared for independence, did not have the structures and experiences essential to enable them to shoulder the burdens of the modern state, making it vulnerable to competing countries, a global, regional, sought to attract more or less for influence on its future political and the pattern of international relations, and these competitions implicit competition between Saudi Arabia and the Islamic Republic of Iran, which Tstkhaddman the religious factor to attract these republics in Central Asia. Being the vying for the leadership of the Muslim world. And took the SaudiIranian rivalry towards the republics of Central Asia, methods, and many activities are focused in working to promote religious and
\end{abstract}


cultural relations as well as economic and political support of these republics.

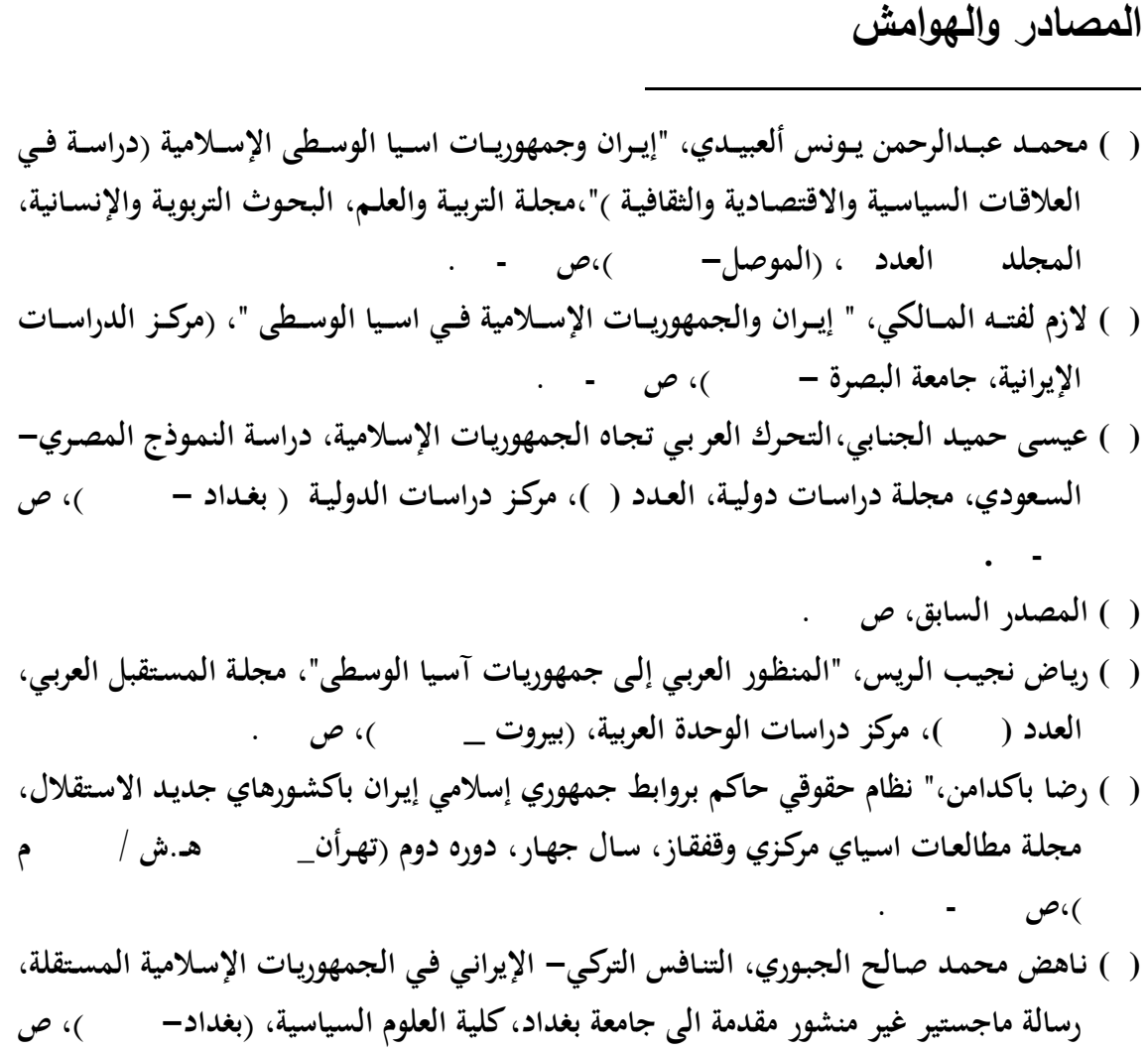

(^) Saleh M. Al-Khatla, "Saudi Foreign Policy Towards Central Asia", Economics and Administration Journal, Vol. I $\}$, No.), ( Riyadhr....), p r r. 
(9) A. Ehteshami, 'New Frontiers: Iran, the GCC and the CCARs' in A. Ehteshami (ed.), From the Gulf to Central Asia: Players in the New Great Game, University of Exeter Press, (Exeter- 199 \&), p १ V.

( 1 - ) J. Calabrese, Revolutionary Horizons: Regional Foreign Policy in PostRevolutionary Iran, St. Martin's Press, (New York, 199 \&), p. $\wedge$ ०.

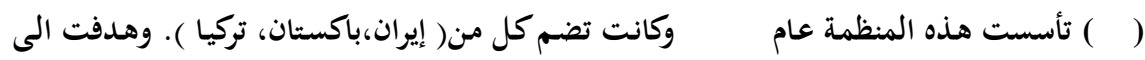

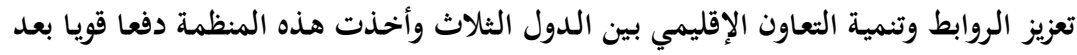
دخول الجمهوريات الإسـلامية المستقلة في قمسة طهران

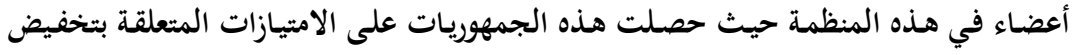

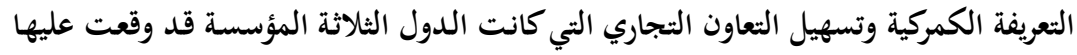

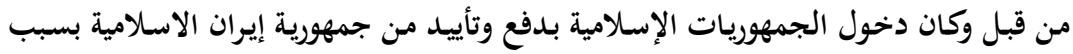

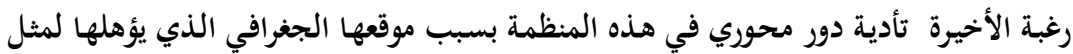
هذا الدور، للمزيد ينظر : عبدالجبار عبد مصطفى، "التنافس التركي الإيراني والأفاق المستقبلية

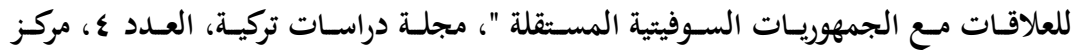

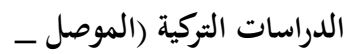

( 1 r) M.E. Ahrari, The New Great Game in Muslim Central Asia, Institute for National Strategic Studies,, (Washington - । 9 ४), pp. §१-०.. (I) Ibid, p. ๑..

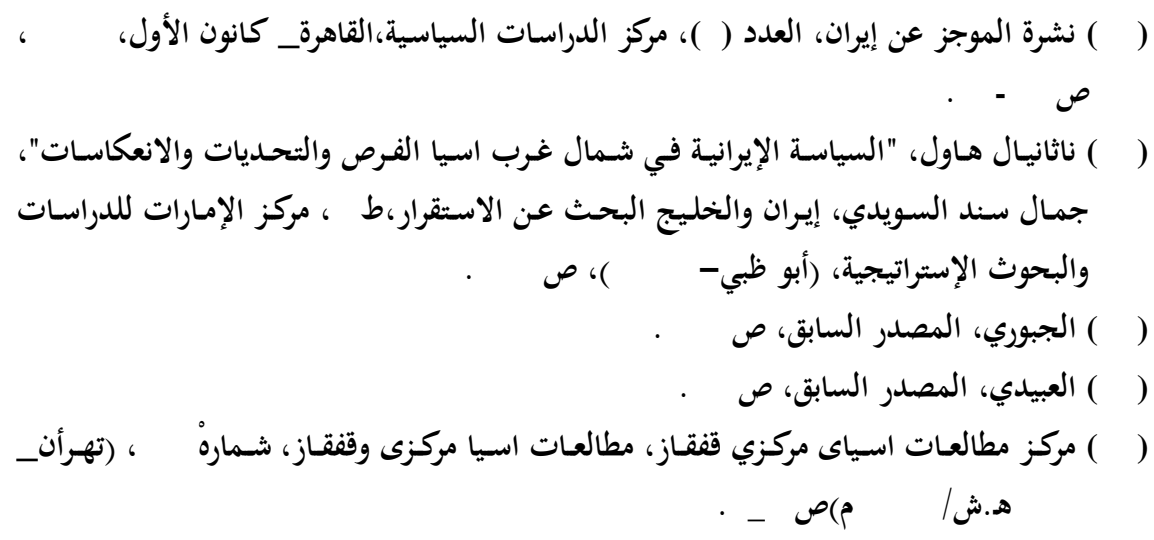




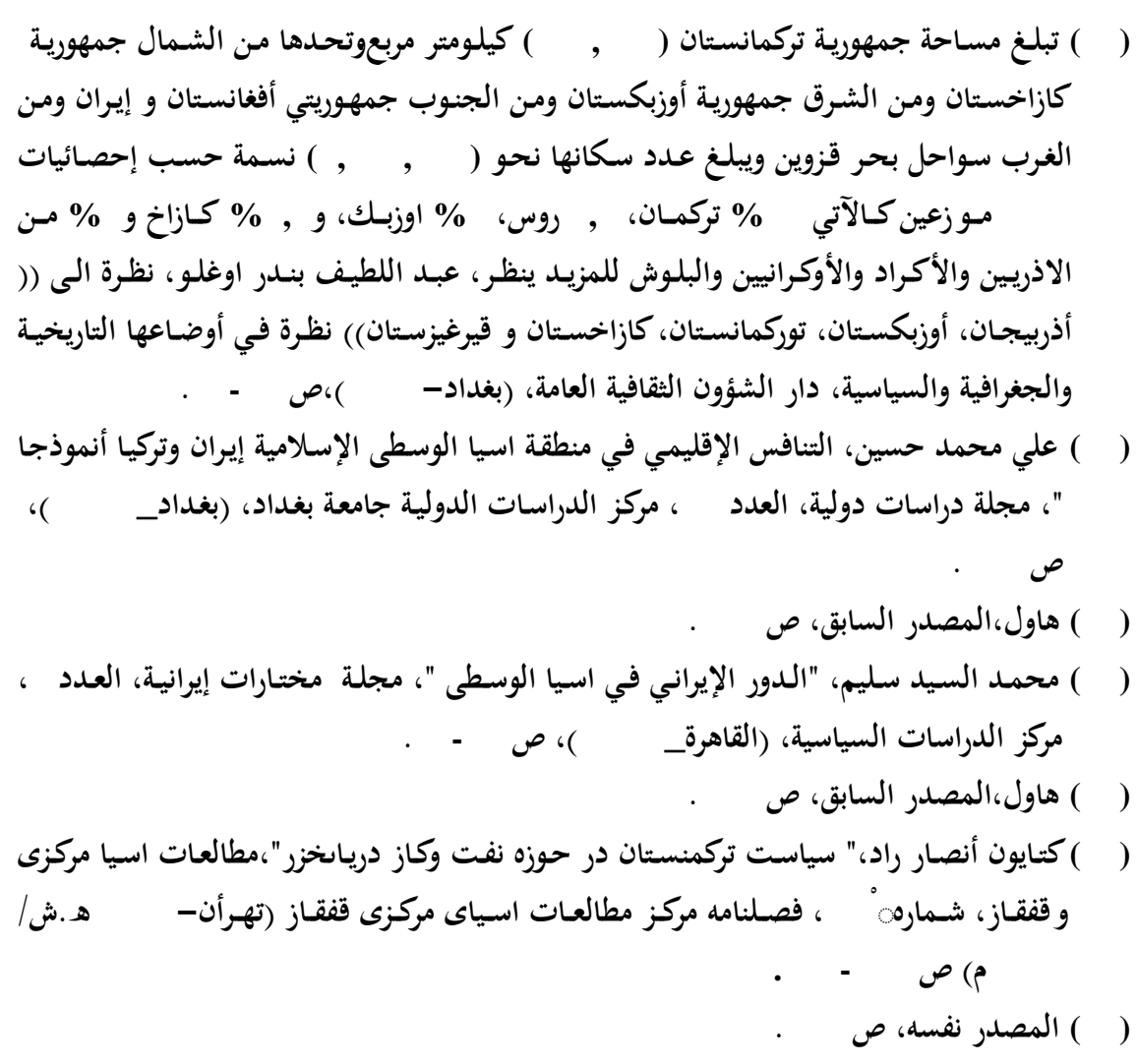

(ץч) K.L. Afrasiabi, After Khomeini: New Directions in Iran's Foreign Policy, Westview Press, 19 १ ), p. 1 \% . (Boulder_

(rV) V. Piacentini, 'Islam: Iranian and Saudi Arabian Religious and Geopolitical Competition in Central Asia' in A. Ehteshami (ed.), , From the Gulf to Central Asia: Players in the New Great Game, University of Exeter Press, (Exeter_ 19 १६) p. $r$ ^.

( $\wedge$ ^) Ibid.,p, §).

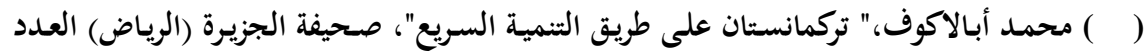

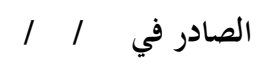


$(r \cdot)$ Henner Fürtig, Iran's Rivalry with Saudi Arabia Between the Gulf

Wars, Cornell University Press (Ithaca_ $r \ldots r),, p r \cdot v$.

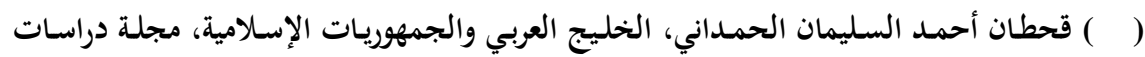

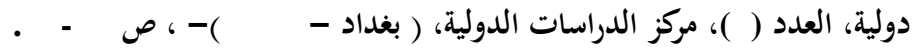

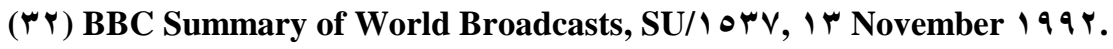

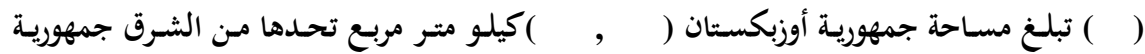

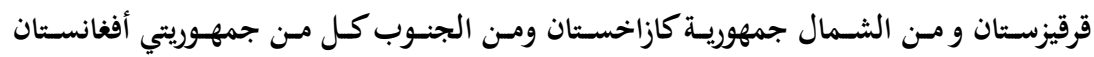

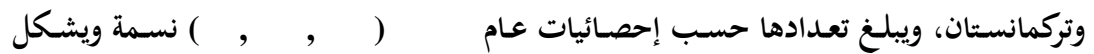

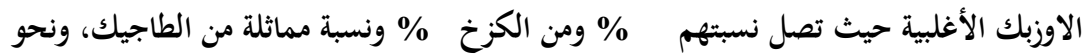

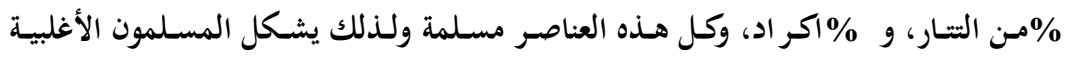

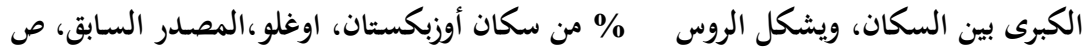

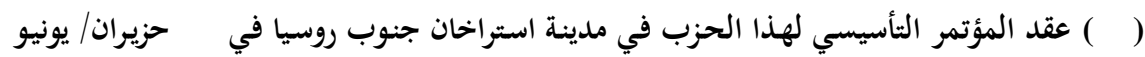

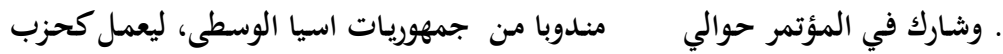

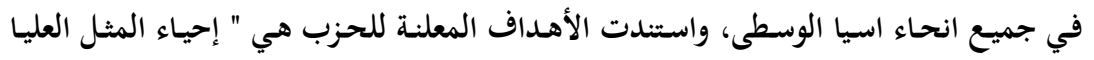

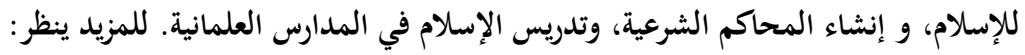

M. Haghayeghi, Islam and Politics in Central Asia, St. Martin's Press,

(New York- 1990), p ^८-^ฯ

(ro) Ibid, p. $\wedge$ ฯ.

(rч) Afrasiabi, Op, Cit, p. I rv.

(rV) Ibid, p. I rv.

(r^) Ibid, p, I rv.

(५ ৭) Edmund Herzig, " Regionalism, Iran and Central Asia", International

Affairs, Royal Institute of International Affairs, Vol. A., No. r, (London- May, $\left.Y_{\ldots} \ldots \varepsilon\right), \mathrm{p} \bullet \cdot V_{\text {.. }}$

(६ • ) H.Y. Freij, 'State Interests vs. the Umma: Iranian Policy in Central

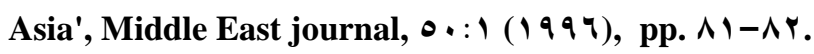

(§ ) Furtig, Op Cit, p r .q 
( $\&$ Y) A. Rashid, The Resurgence of Central Asia. Islam or Nationalism?, Zed Books, (London_1 9 १ ), p. $1 \cdots$

( $₹$ r) Ehteshami, Op, Cit, p. $9 \vee$.

( $\varepsilon \varepsilon)$ Ibid, p. १V.

( ६ ४) Ehteshami, Op, Cit, p. १マ.

$$
\text { ( ) ( ) (الحمداني، المصدر السابق، ص }
$$

(६^) Rashid, Op, Cit, p. $1 \cdots$

( ₹q) Ibid , p. $1 \ldots$

(๑.) John Kohan, Central Asia Asks, Who are We? The Time London, April $r \cdot, 199$ rp. $\varepsilon$.

( وليد محمود عبد الناصر، إيران نحو الحسم والتصعيد أم الاستمرار، مجلة السياسية، العدد

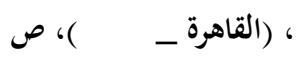

(or) Rashid, Op, Cit, p. 1..

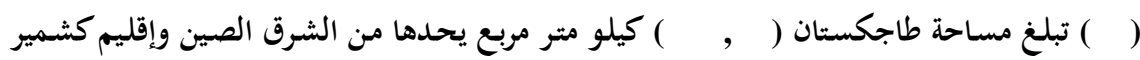

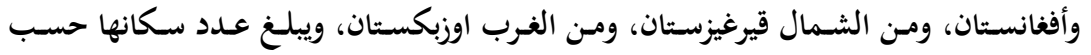

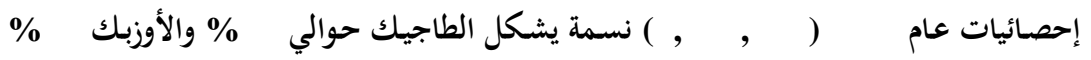

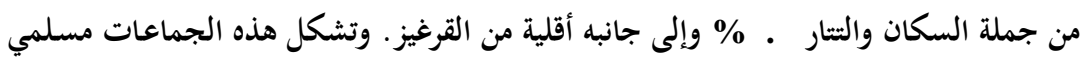

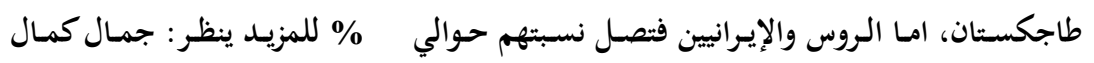

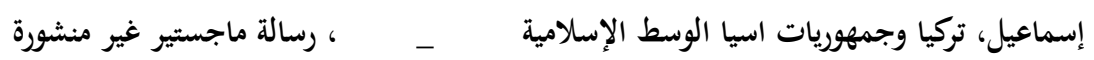

(॰ ६) Furtig, Op Cit, p r.r.

(๑৩) Haghayeghi Op, Cit, p. $\wedge \vee$.

( موريل اتكين،" روابط إيران وتاجيكستان " مجلة مطلعات اسياي مركزي وقفقاز، مركز مطلعات

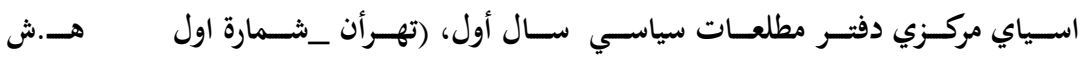

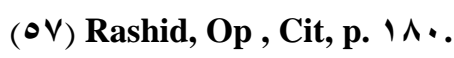

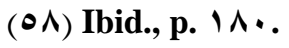


( احسد قـادة المعارضـة والـئيس الأعلى للهيئسة الإسـلامية الرسـمية ورئسيس مليشسيا(قـوات غيـر

Rashid, Op, Cit, p.

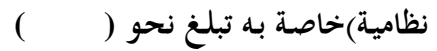

$1 \wedge$.

( ) Ibid.,p. $1 \wedge \cdot$.

( ) ( ) الأبجدية السريلية هي أبجدية سلافية قديمة يستخدمها الروس.

( 7 y) M. Atkin, 'Iran's Relations with Tajikistan, US-Iran Review, 1:7 $(199 \mu)$, p.

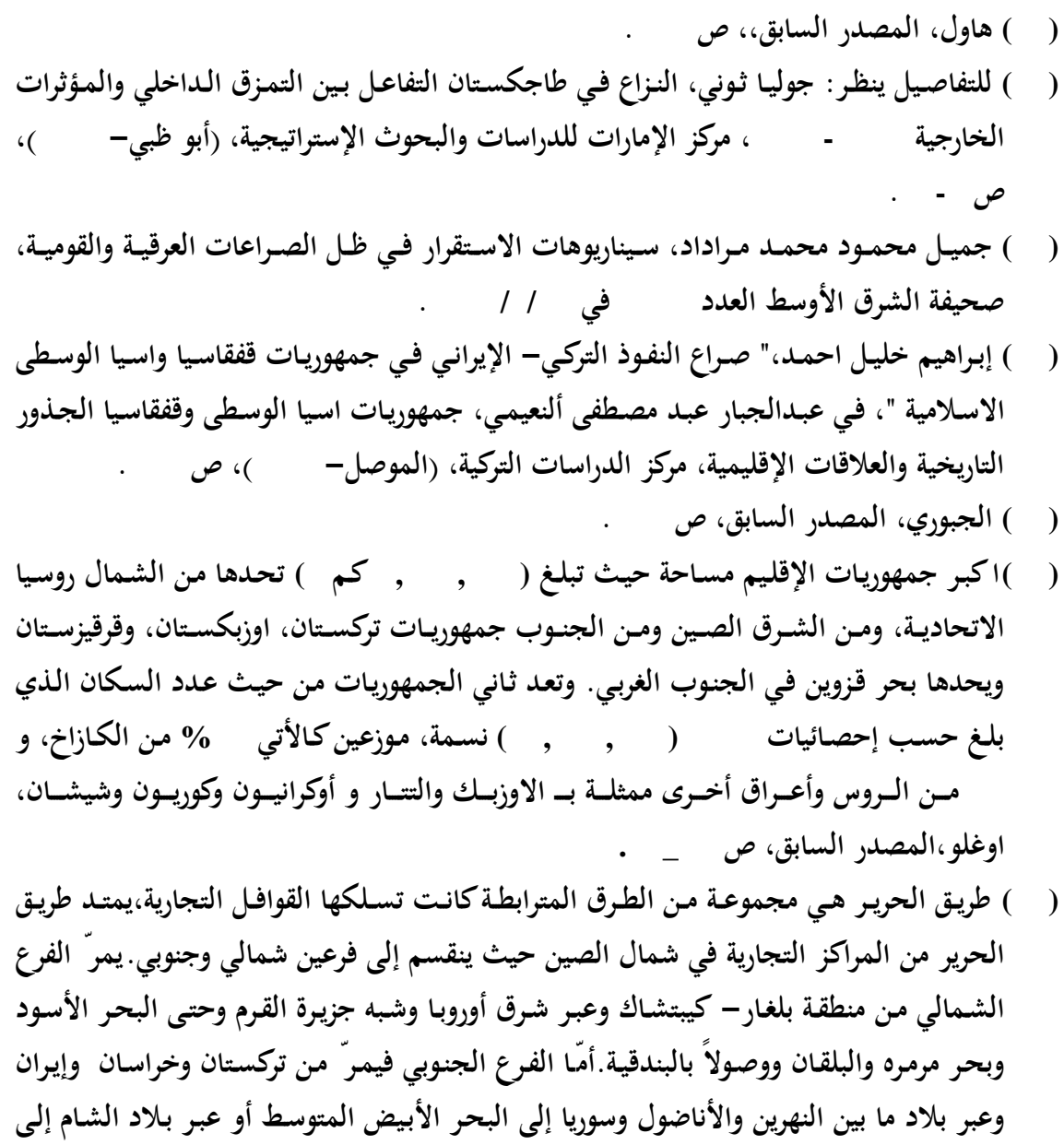




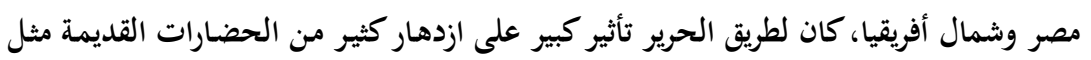

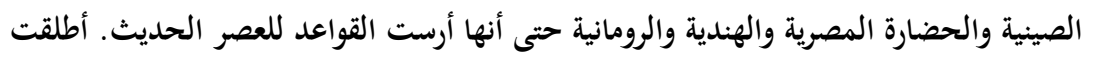

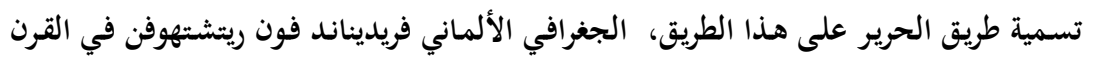

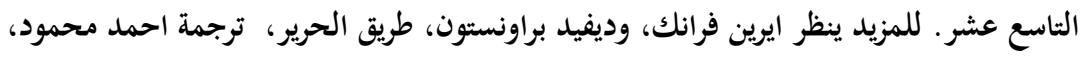

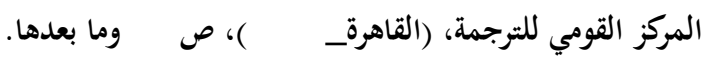

(V.) Afrasiabi, Op, Cit, p. I Ү .

(V ) Furtig, Op Cit, p r.r.

(Vr) Afrasiabi, Op, Cit, p. I ฯ.

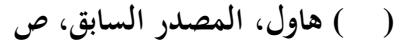

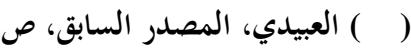

(v৩) Afrasiabi, Op, Cit, p. I ฯ .

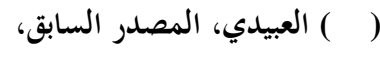

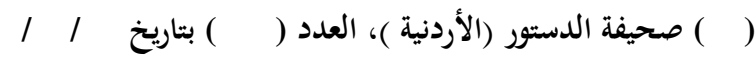

(VA) Al-Khatla, Op, Cit, p rr.

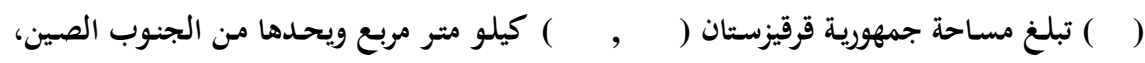

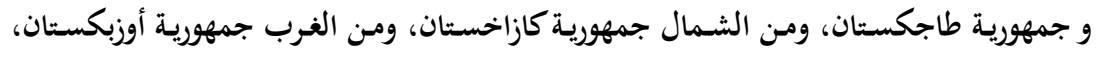

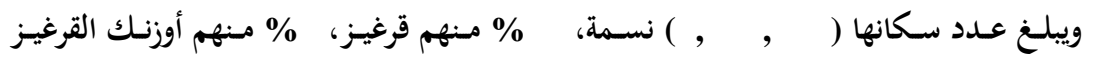

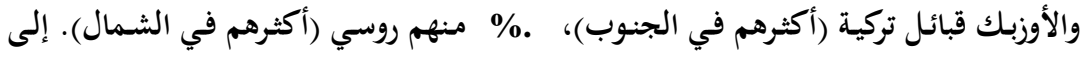

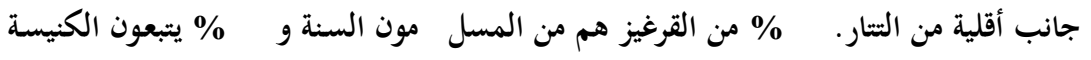

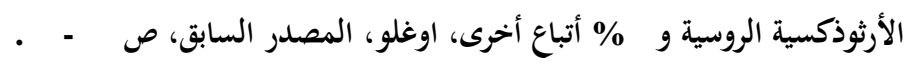

( ) Haghayeghi, Op,Cit, p. Y ).

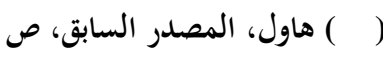

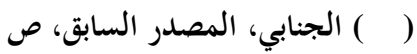

(৯ץ) Ehteshami , Op ,Cit, p. $1 \cdot \wedge$. 